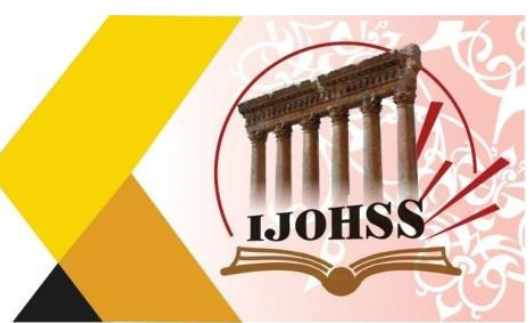

\title{
ثقويم أداع مدرسي مادة علم الأحياء في ضوء مهارات القرن الحادي والعشرين
}

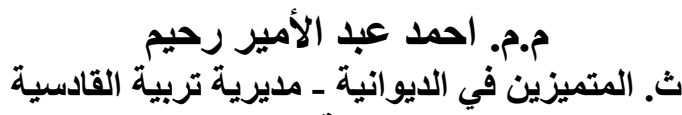

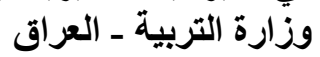 \\ ahsm755@yahoo.com
}

\begin{abstract}
الملخص

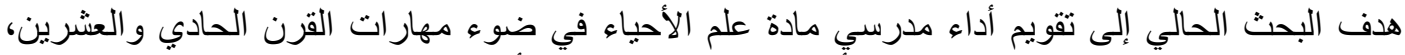

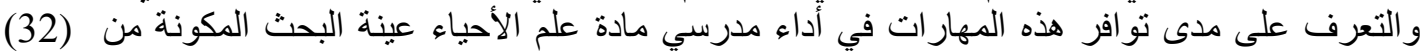

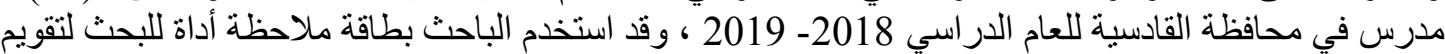

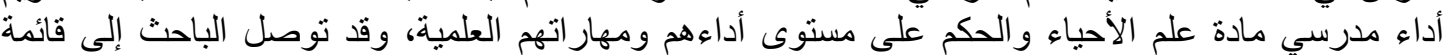

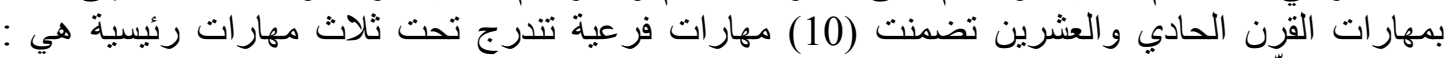

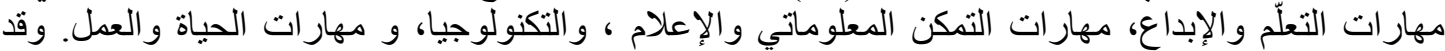

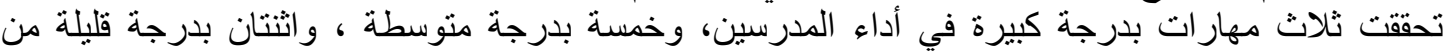

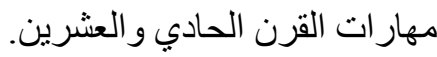
الكلمات المفتاحية: تقويم أداء، علم الأحياء، مهار ات القرن الحادي و العشرين.
\end{abstract}

\section{Evaluating the Performance of the Teachers of Biology in Light of the $21^{\text {st }}$ Century Skills}

\author{
Ahmed Abd Al-Ameer Raheem \\ Directorate Of Education In Diwaniyah - Iraq \\ ahsm755@yahoo.com
}

\begin{abstract}
This research aimed to Evaluating the performance of the teachers of biology in light of the 21 st Century skills , and identification the availability of this skills in the performance of teachers of biology (32) teachers in Al-Qadisiyah 2018-2019 . The researcher has used an observation as a tool for valuating and judging the performance and scientific skills of biology teachers. The researcher has formulated a list of learning dimensions skills including (10) skills Learning and innovation, Information, Media and Technology, and Life \& career skills. The finding has proved that three skills highly statistically significant of teacher performance, five are moderately statistically significant to teacher performance, and two are low statistically significant to teacher performance.
\end{abstract}

Keywords: performance evaluation, biology, twenty-first century skills. 


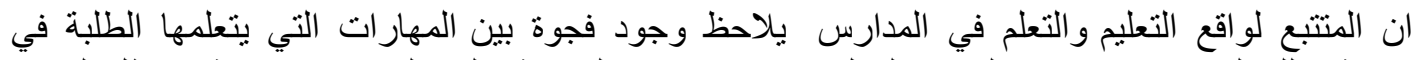

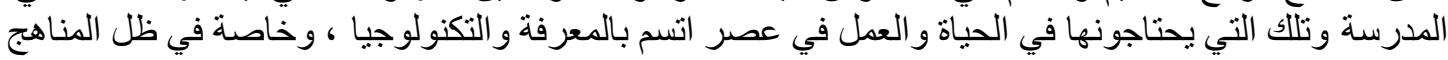

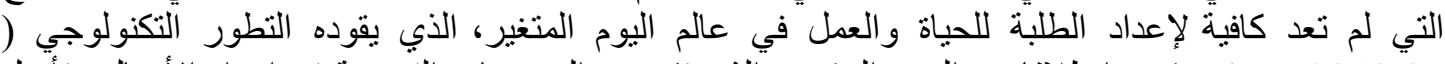

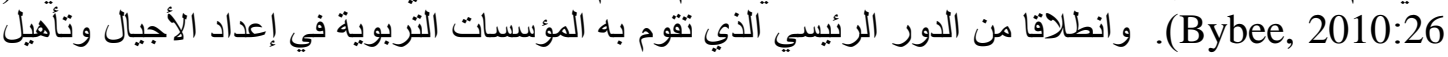

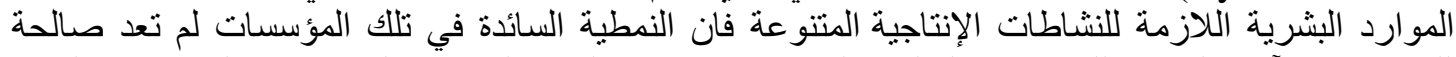

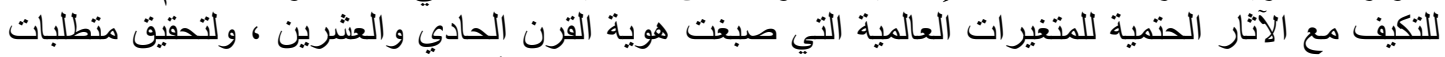

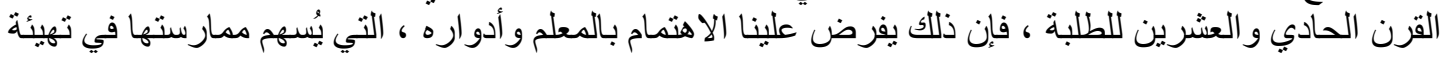

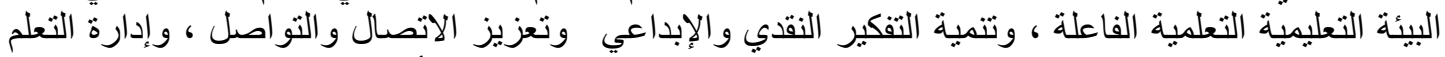

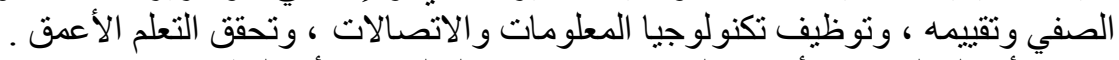

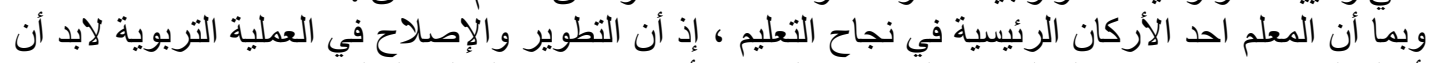

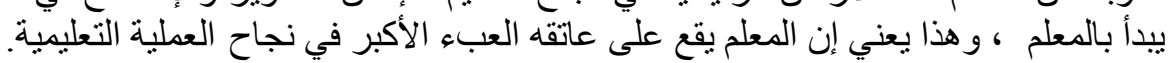

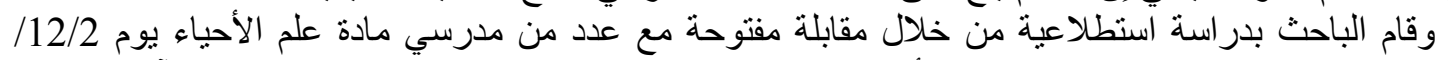

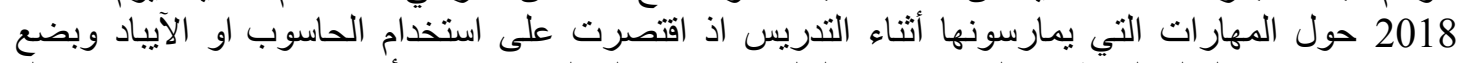

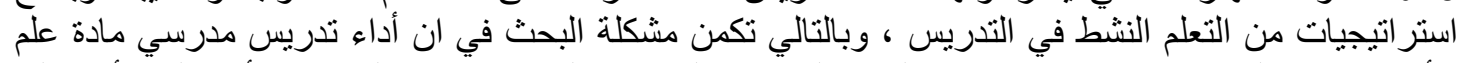

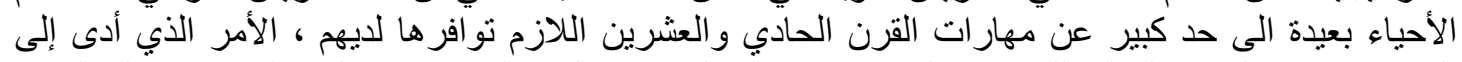

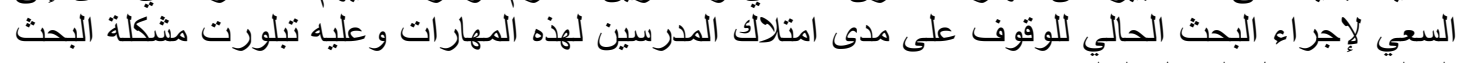

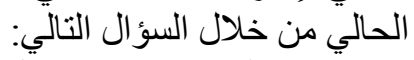
مامدى امتلاك مدرسي مادة علم الأحباء لمهار ات القئ القرن الحادي و العشرين؟

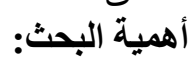

في مطلع القرن الحادي و العشرين جابهت المجتمعات المعاصرة الكثير من المشكلات ذات العلاقة باتلة بالعولمة

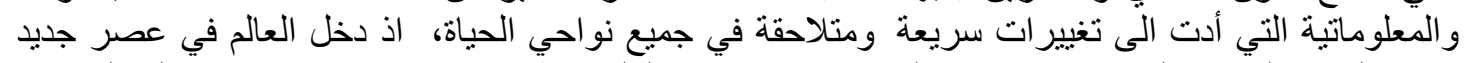

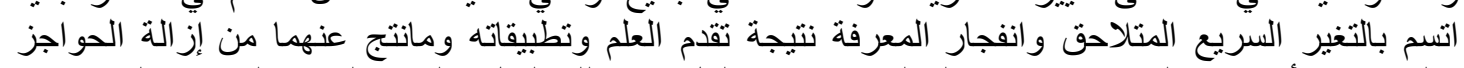

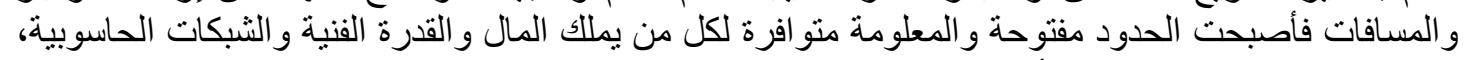

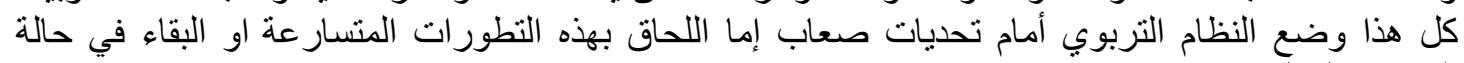

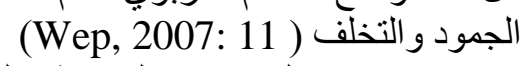
و هذا يعني إن المؤسسات التربوية والنعليمية مطالبة بتنبي الرؤى التطويرية الجديدة والإقلاع عن الممارسات

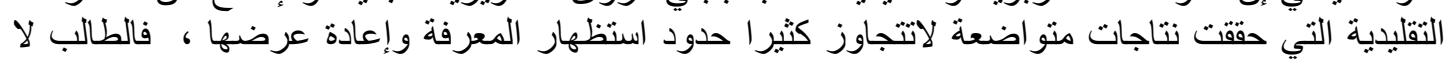

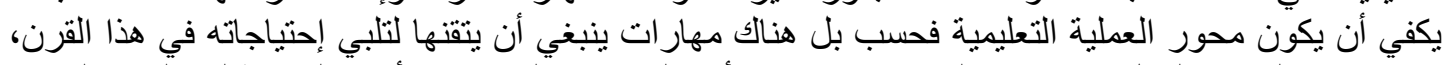

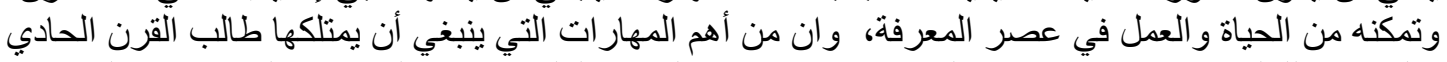

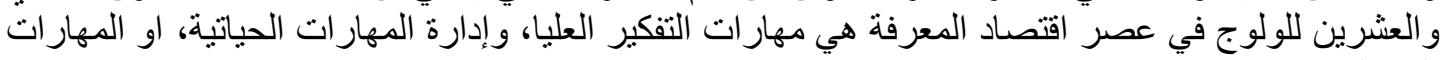

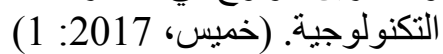
كما ان التقدم الهائل والتغير ات ات السريعة التي تحدث في هذا العصر جعل المؤسسات التعليمية تسعى لمواكبة

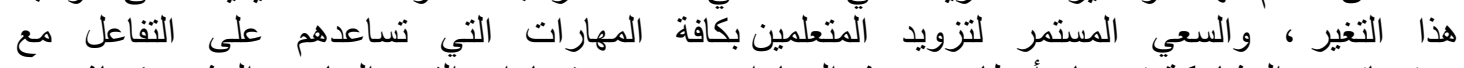

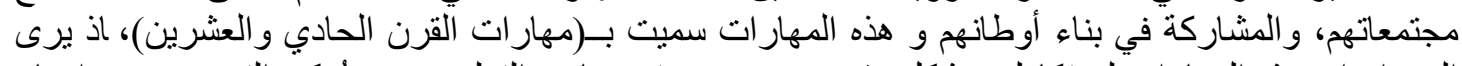

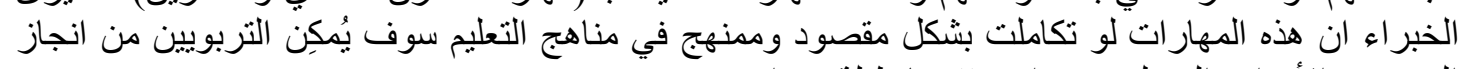

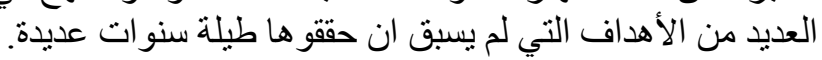

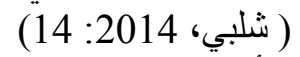

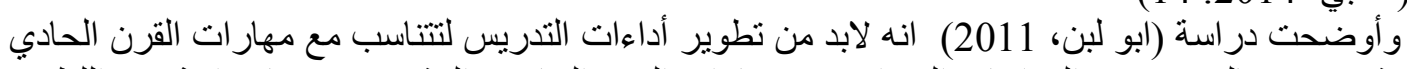

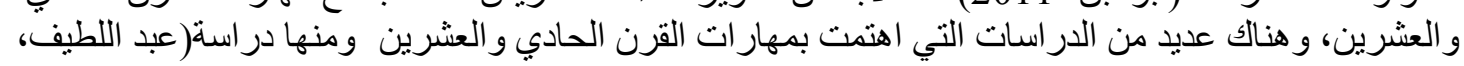

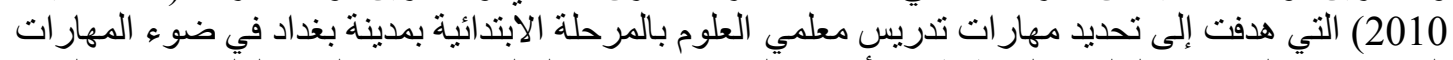

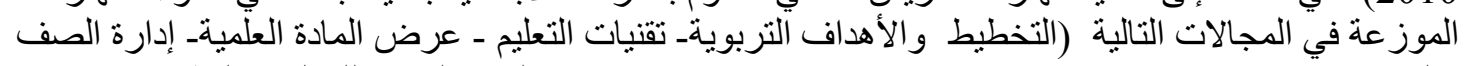

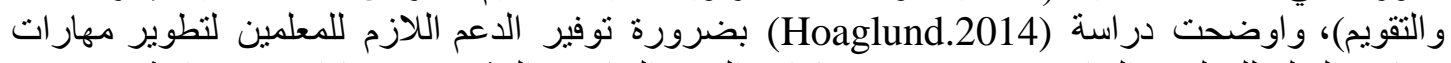

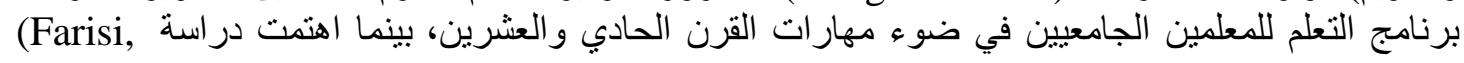


(2016 بتطوير ثلاث مهار ات أساسية لمعلم القرن الحادي و العشرين في العصر الرقمى وهي( مهار ات اتلات التعلم

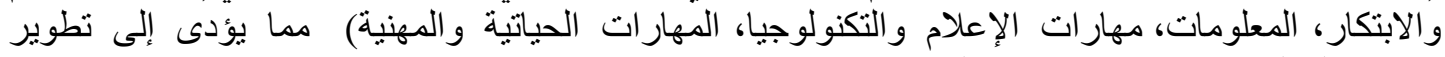

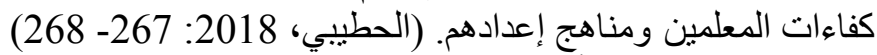

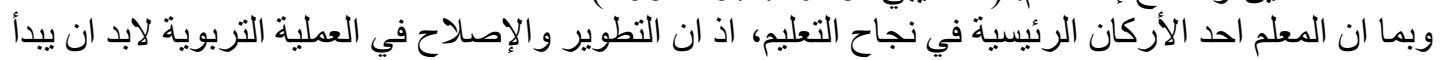

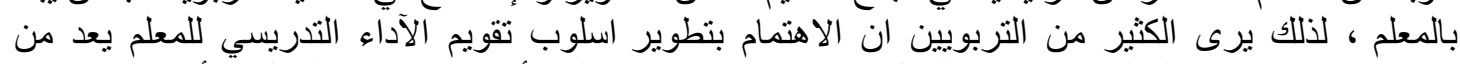

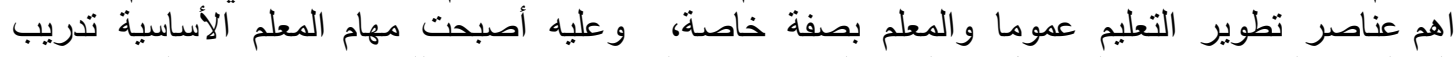

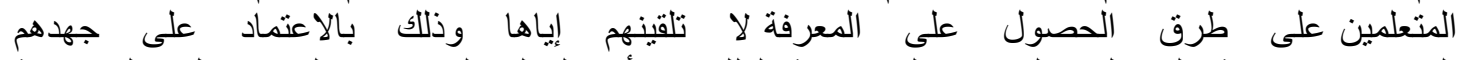

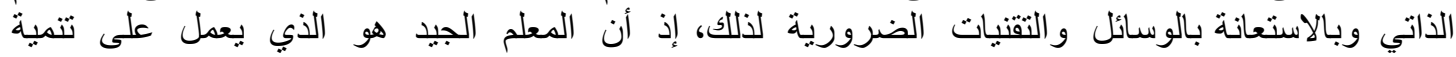

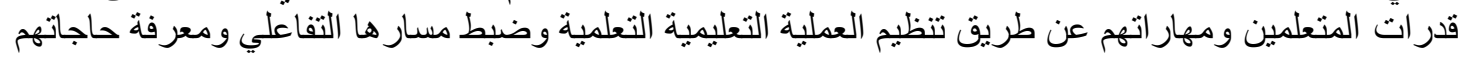

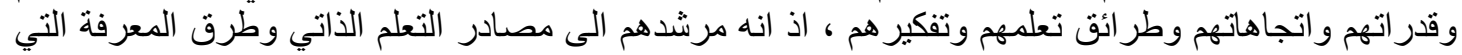

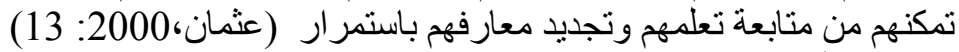

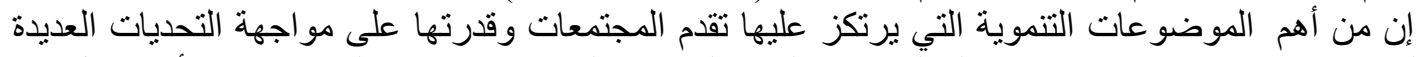

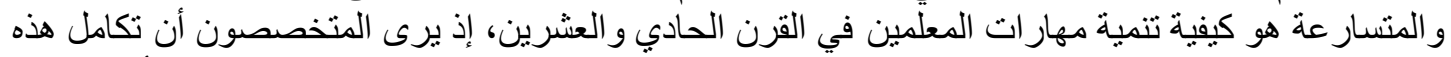

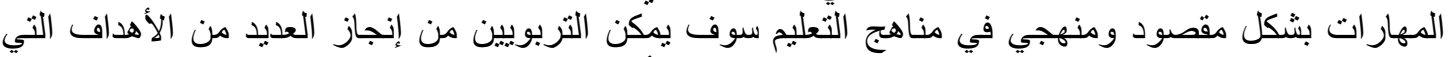

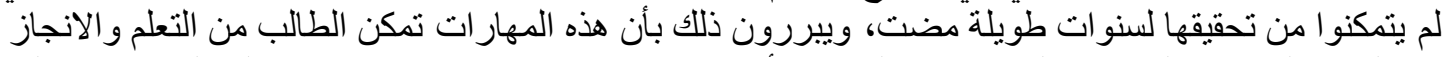

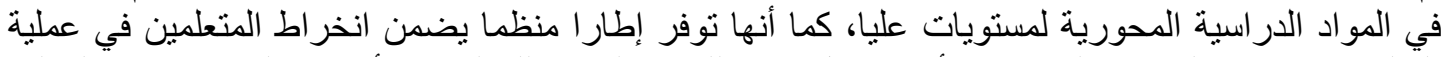

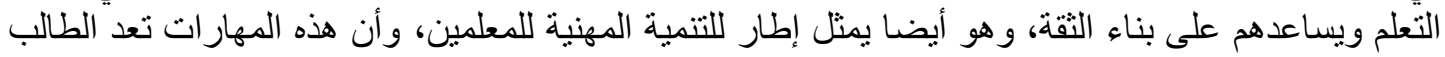

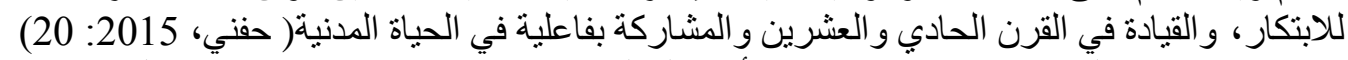

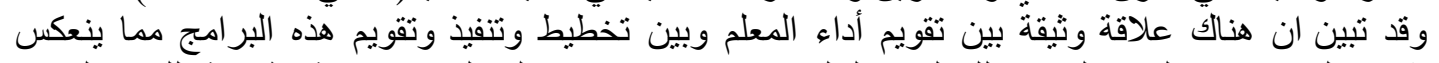

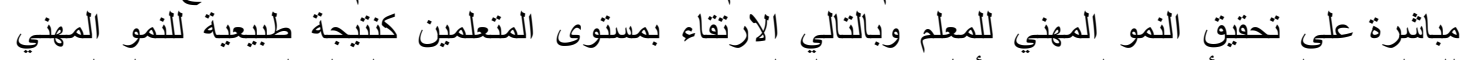

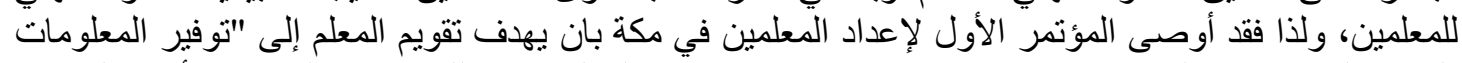

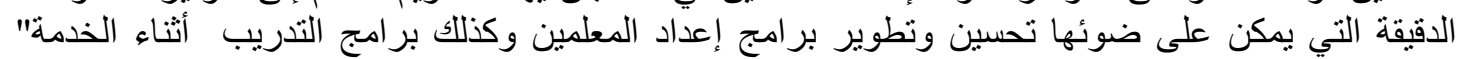

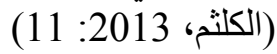

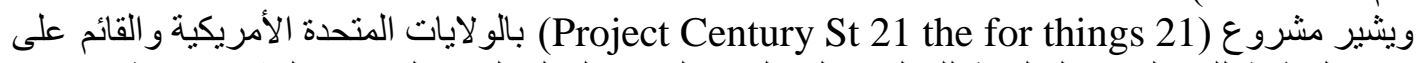

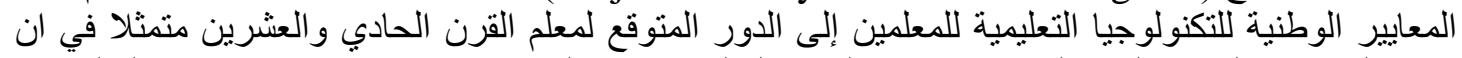

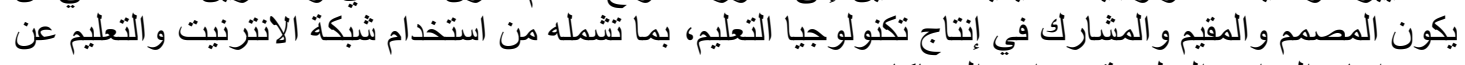

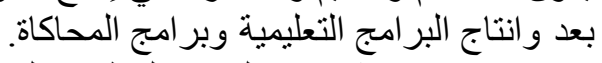

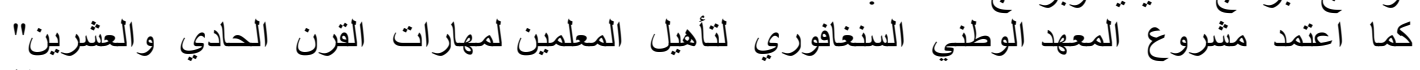
اذ Century St 21 the for Education Teacher, Eductors Techer Model Singapore A

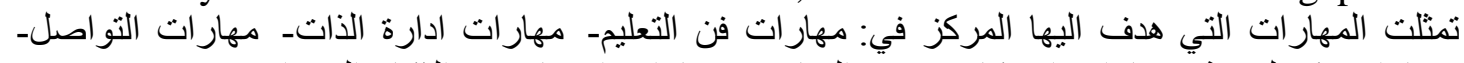

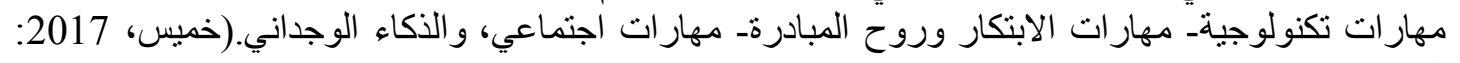

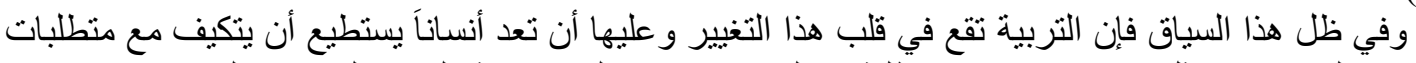

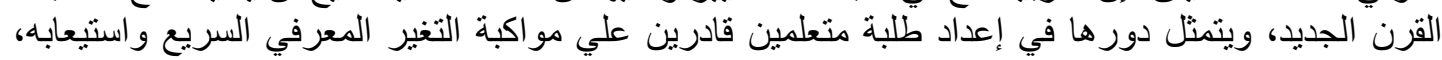

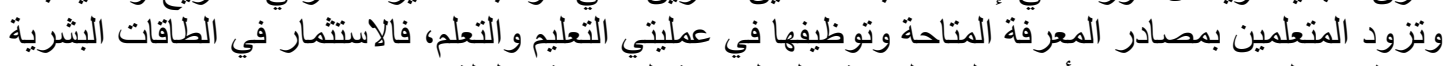

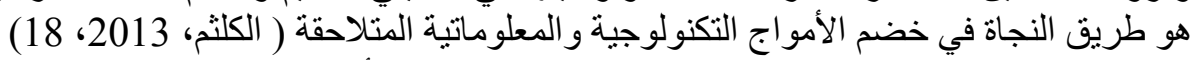

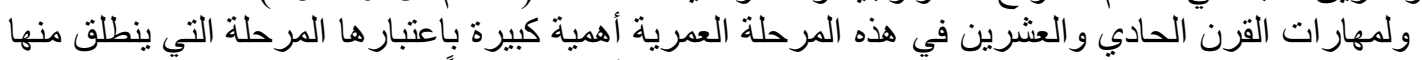

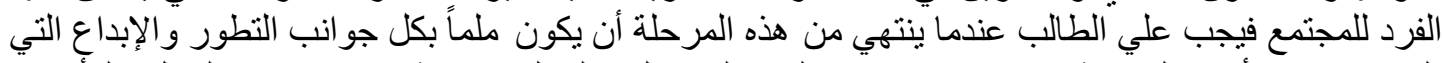

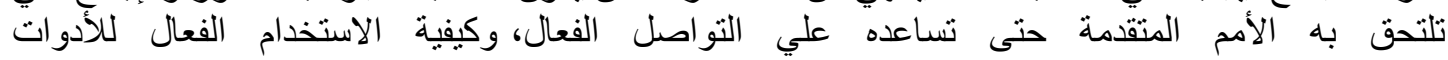
التكنولوجية، والقدرة علي مواجهة التحديات التي نعيش فيها بسبب التطور و التقدم الذي نشهده في هذا العصر. (تشلبي، 2014: 4) ويمكن ان تتجلى أهمية البحث الحالي:

1- الارتقاء بعملية تقويم المدرس بانية الاستفادة من نماذج تقويمية عالمية لذلك فان أهيته تتبثق من أهمية عملية

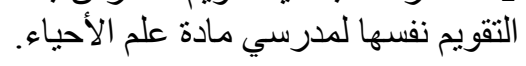




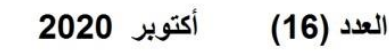

Volume (16) October 2020

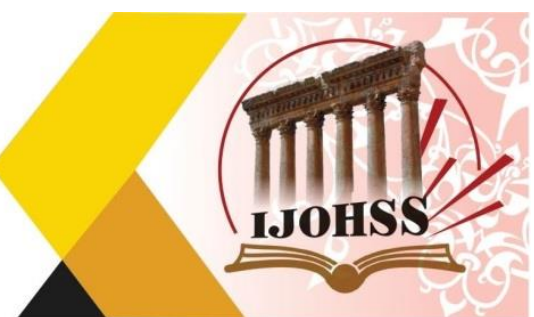

2- يقدم هذا البحث لوزارة التربية تصورا عن أهم الأبعاد التعلمية التي يجب أن تتوفر لدى مدرسي مادة علم الأحياء.

3- يساعد هذا البحث مدرسي مادة علم الأحياء على معرفة أدوارهم المهنية و المهارات التي يجب عليهم

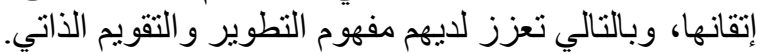

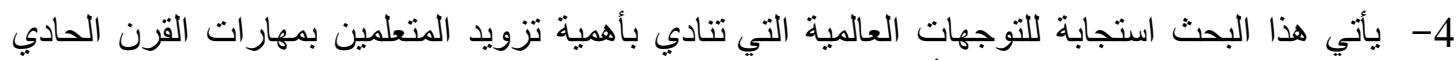

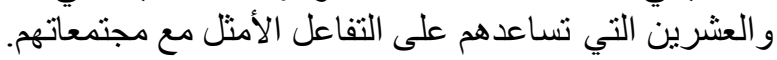

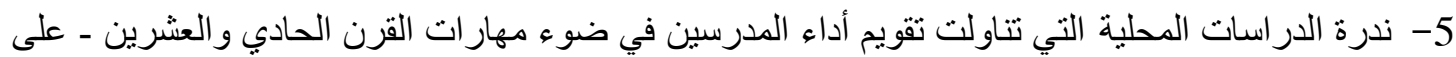

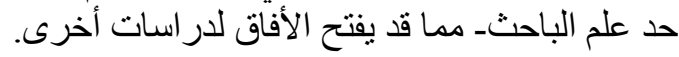
6- يتناول هذا البحث عنصرا أساسياً من عناصر التهات العملية التربوية التعليمية وهو المدرس من حيث خصائصه ومهار اته و وإمكانياته.

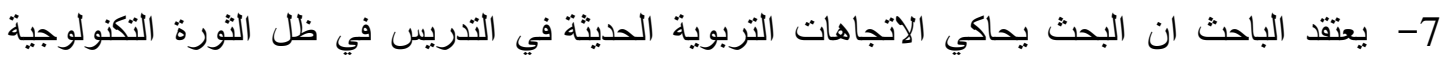

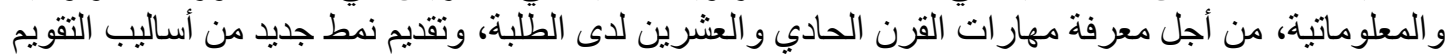
يختلف عن الاساليب التقويمية التقليدية ويعتمد علي مدى إبداع المعلمين و الطلبة في إستخدام التقنيات الحديثة في التعليم. 8- يمكن ان تستفيد وز ارة التربية و التعليم من هذا البحث في مر اجعة خططها واستر اتيجياتها وبر امجها نحو

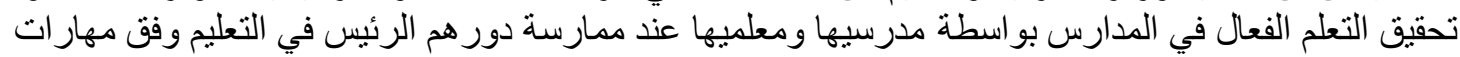
القرن الحادي و العشرين، وتحفيز هم على الإلبداع.

هيدف البحث:

حدود الاراسة:

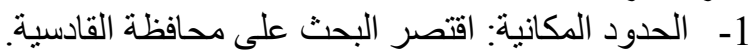

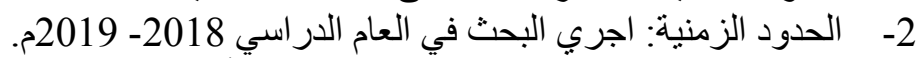

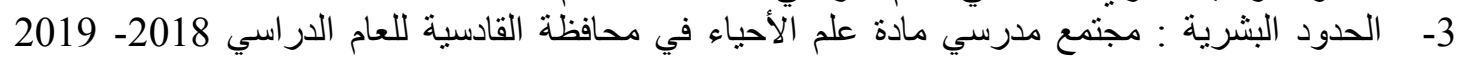

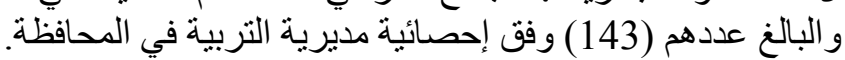
4- مهار ات القرن الحادي و العشرين:

مهار ات التعلّم و الإبداع: وتشمل: التفكير الناقد وحل المشكلات ـ ـ الاتصال و التشارك ـ ـ الابتكار و الإبداع.

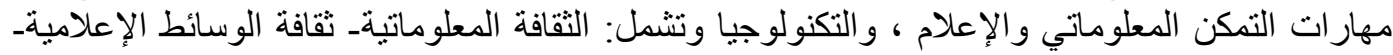
ثقافة تقنيات المعلومات و الاتصناّل. مهارات الحياة و العمل ، وتضم: والمات المرونة و التكيف ـ المبادرة وتوجيه الذات ـ الإنتاجية و المساءلة ـ القيادة

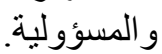

(The National Science Teachers Association ,2013:p 21-22)

تحديا المصطلحات :

1- التقويم: يعر فه (اللقاني و الجمل، 2003): بأنه إصدار حكم تجاه شيء ما او موضوع ما"

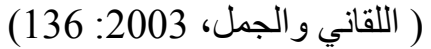

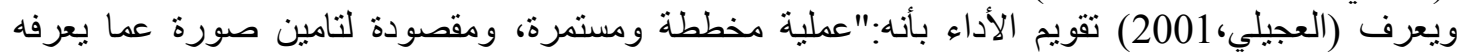

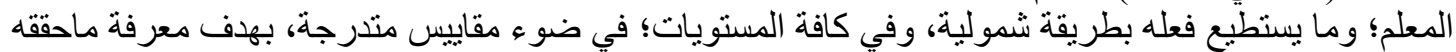

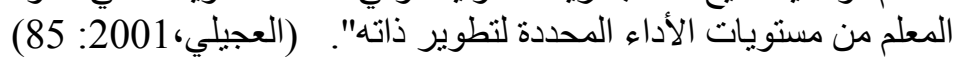




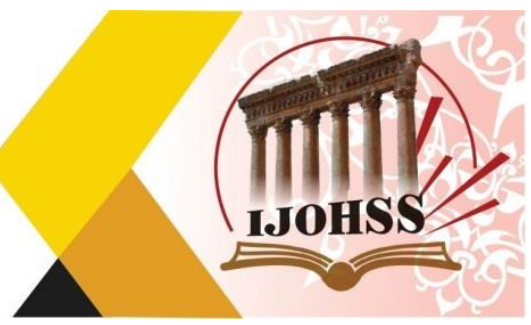

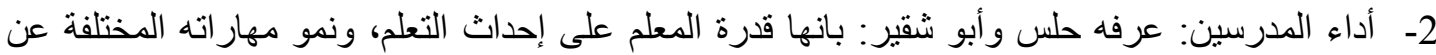

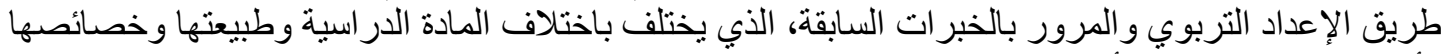

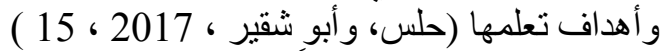

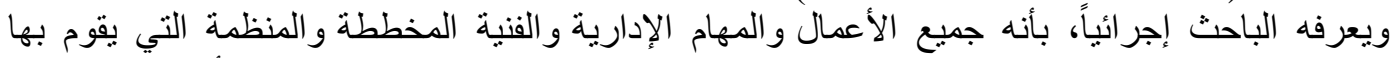

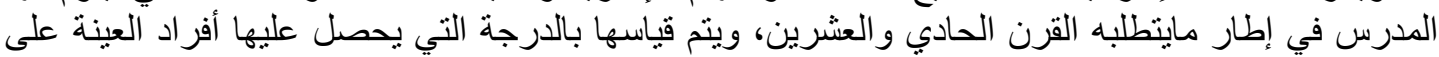

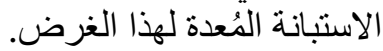

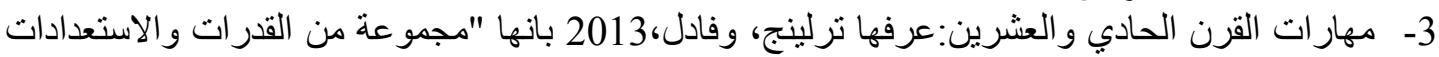

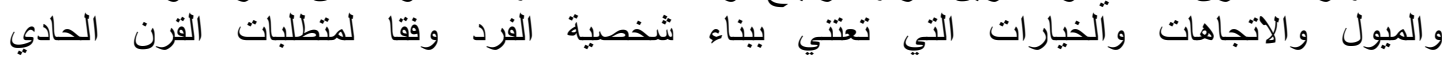

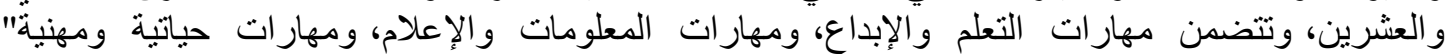

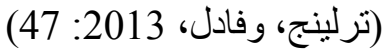

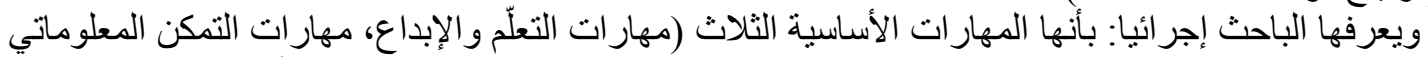

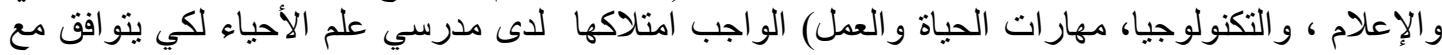

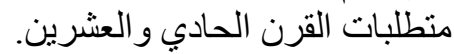

\section{الفصل الثاني/ خلفية نظرية ودراسات سابقة

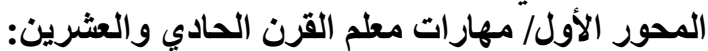

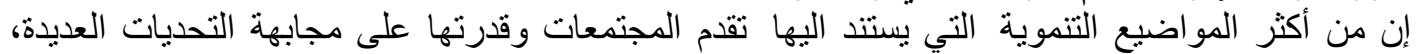

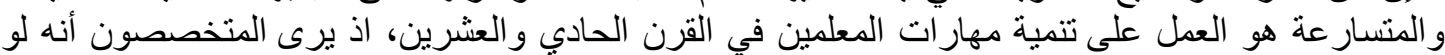

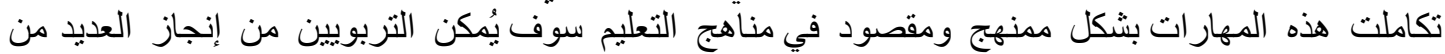

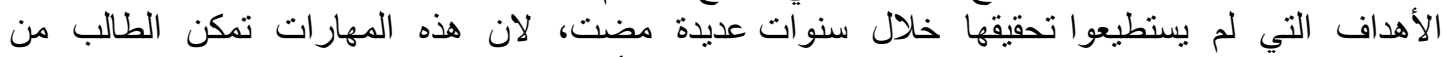

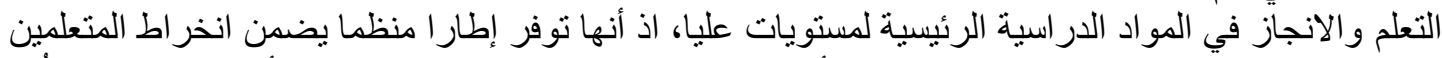

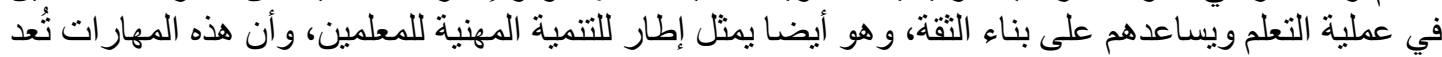

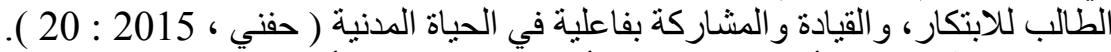

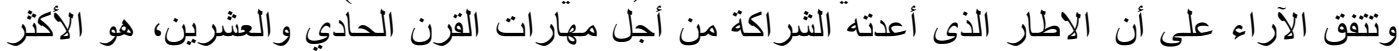

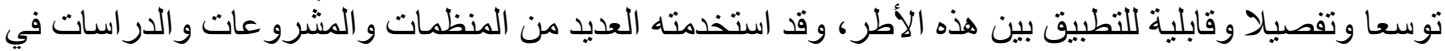

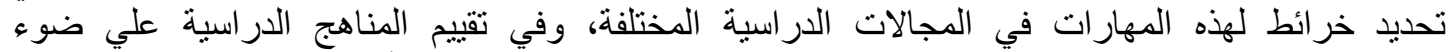

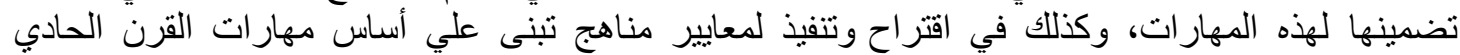

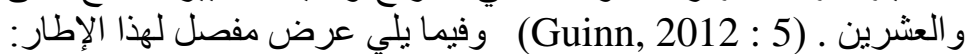

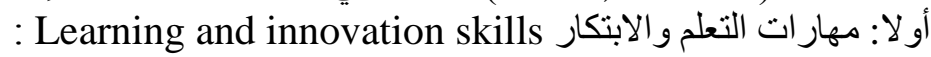

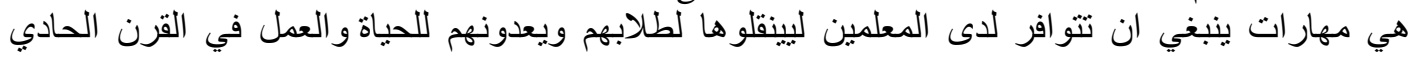

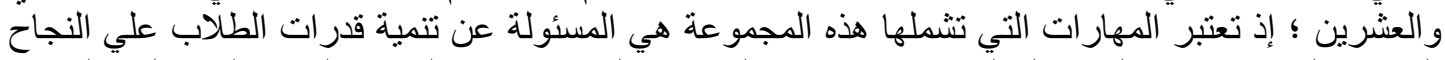

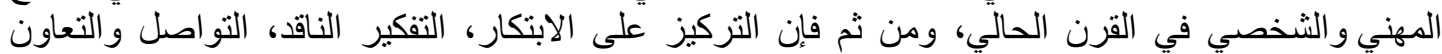

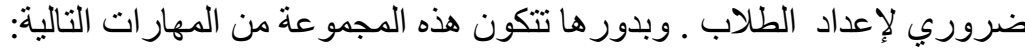

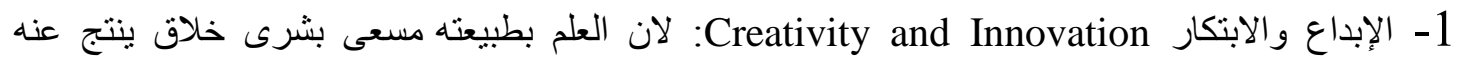

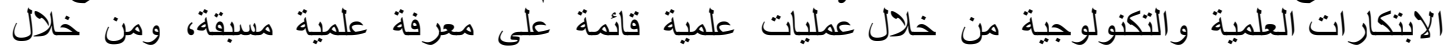

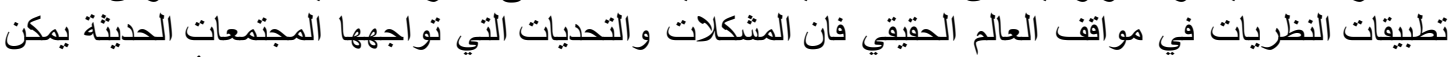

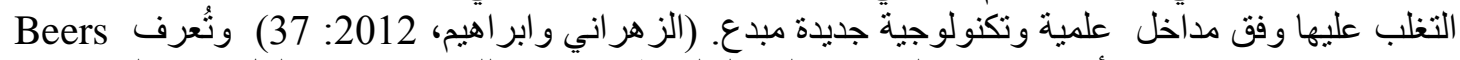

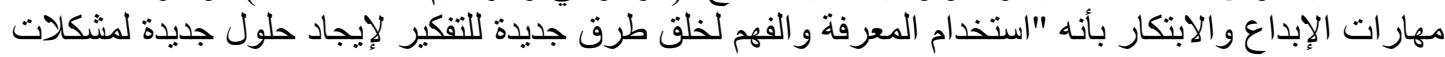

جديدة ولخلق منتجات وخدمات جديدة". (Beers, 2006: 12)

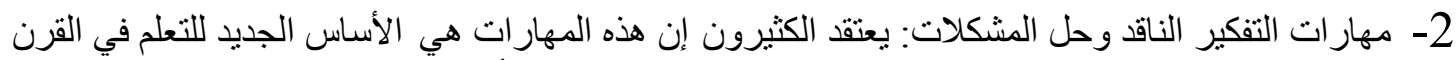

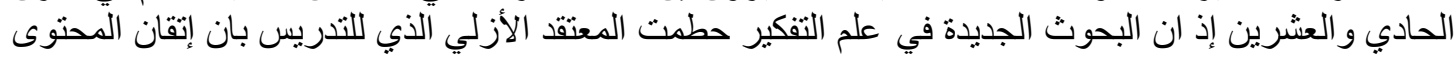

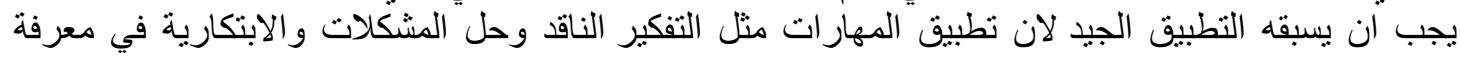

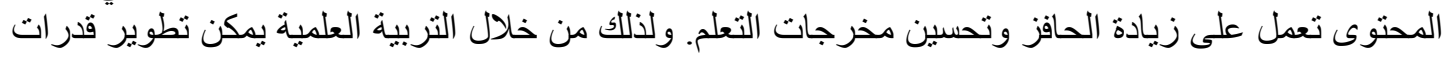


العدد (16) أكتوبر 2020

Volume (16) October 2020

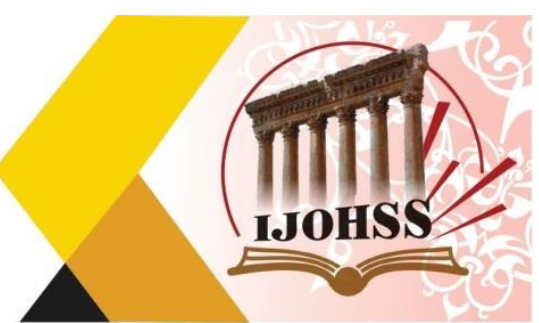

المعلمين علي التفكير حول المفاهيم التي يعلمونها لطلابهر ويطبقونها في حياتهم اليومية؛ حيث يستخدم الطلاب

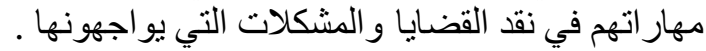

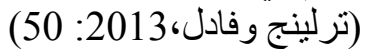

ومهار ات التفكير الناقد: هي"تطبيق مهارات التفكير العليا علي مشكلات وقضايا جديدة باستخدام طرق تفكير مناسبة فعالة لتحليل المشكلة واتخاذ القرارات حول التثر الطرق فعالية لحل المشكلة".

(Beers ,2006 : 14)

3- الاتصال الفعال Effective Communication: العلم بطبيعته عملية تعاونية ويقصد بالتعاون إبراز

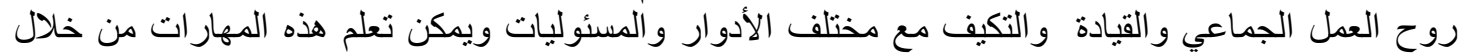

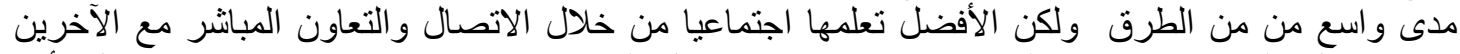

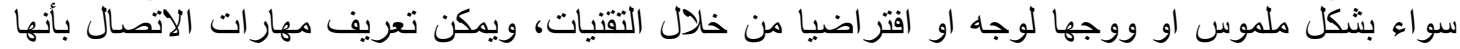

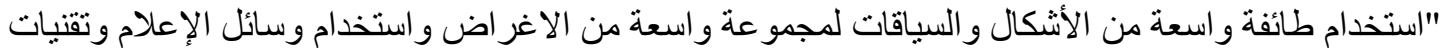

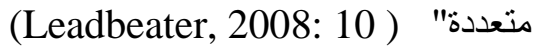

Information, Media and Technology Skills انيا/ مهار ات المعلومات (الوسائط و التكنولوجيا)

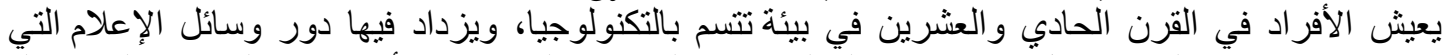

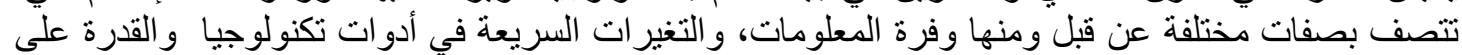

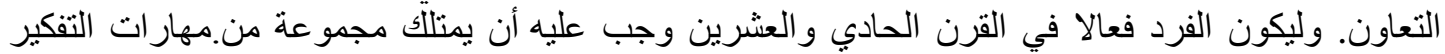

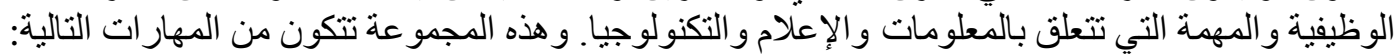

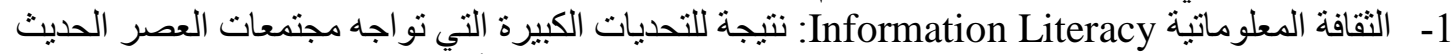

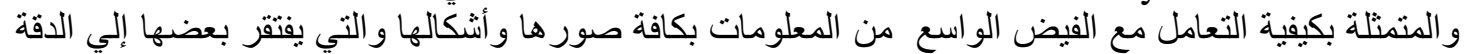

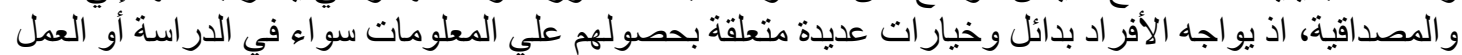

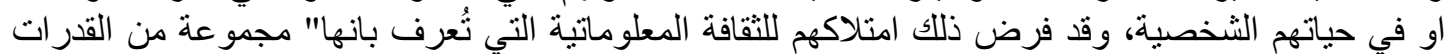
المطلوبة التي تمكن المتعلمين من تحديد احتياجاتهم من المعلومات و الوصئة الوصول إليها وتقييمها ومن ثم استخدامها

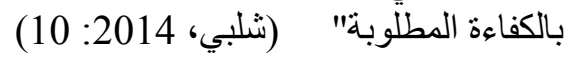

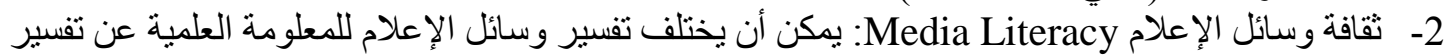

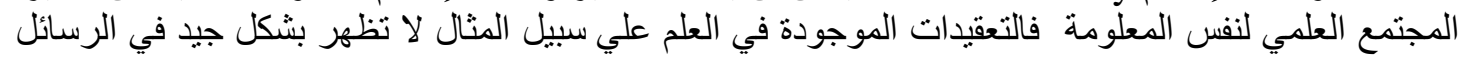

الإعلامية القصيرة. (Facer,2012: 101)

3- نقافة تكنولوجيا الاتصالات و المعلومات (ICT) Literacy

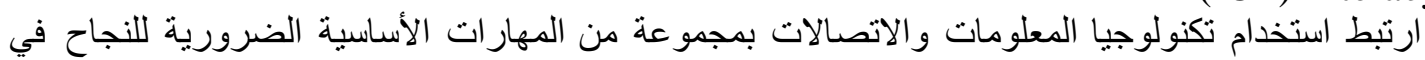

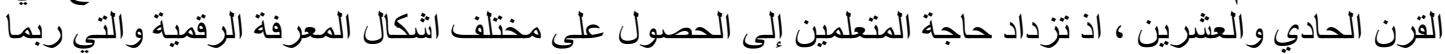
تتجاوز مهار ات الحاسوب الأساسية ليتمكنو المن المشاركة في مجالات الحياة الحياة المتعددة مثل تطبيق التكنولوجيا

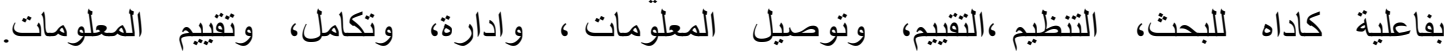

.(McLoughlin and Lee, 2010:p 28)

ثنالثا : مهار ات الحياة والمهنة Life and career skills

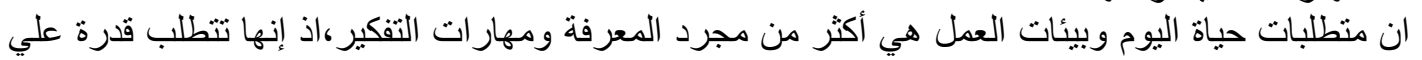

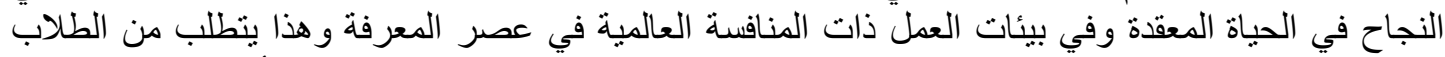

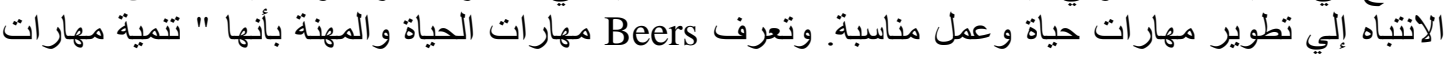

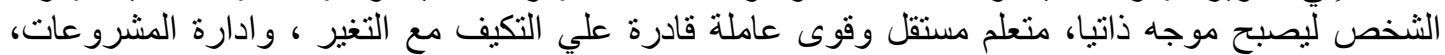

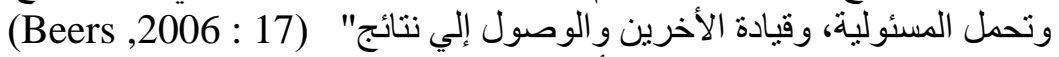

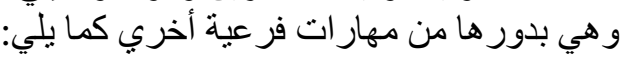

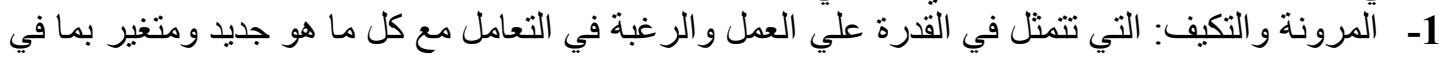

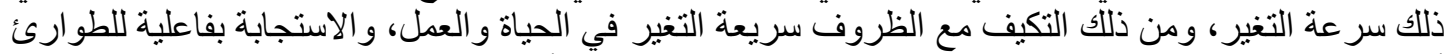

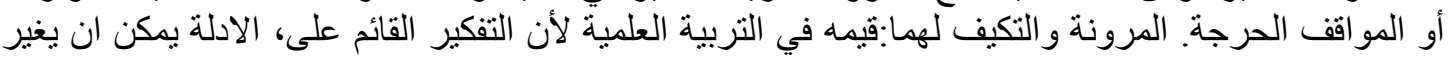




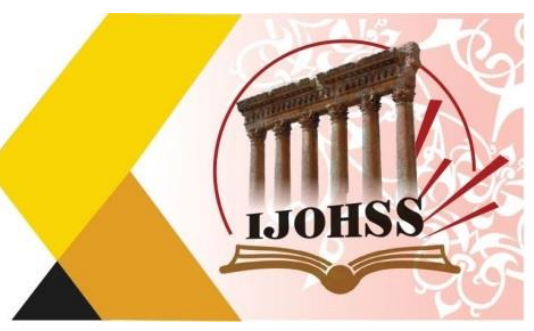

الافكار المسبقة او الفروض وعبر الزمن يؤدى التوسع في الفهم العلمي و التغير في التكنولوجيا إلي خلق مجالات

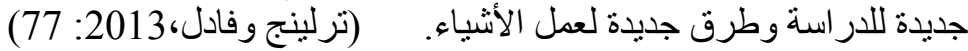

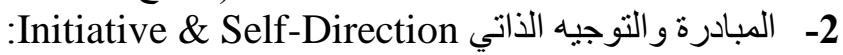

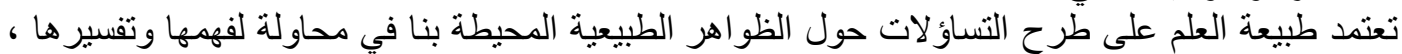

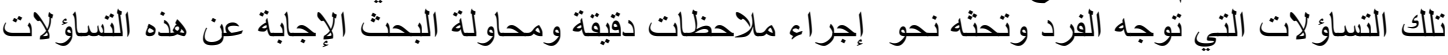

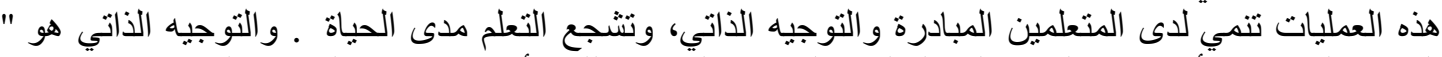

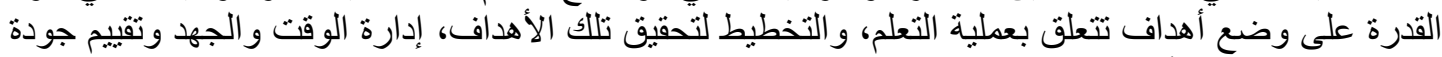

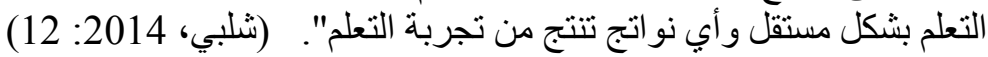
Productivity \& Accountability

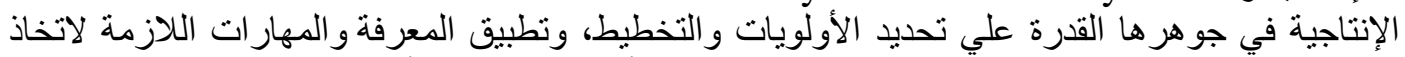

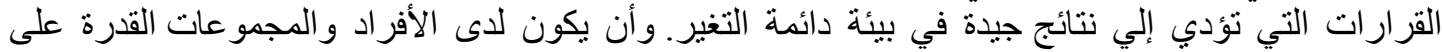

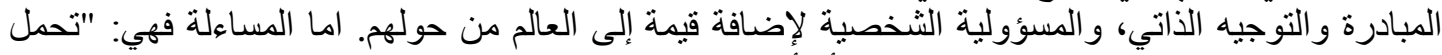
المسؤولية عن الإجر اءات اللازمة لخلق المنتج أو أداء المهمة" (17: Guinn,

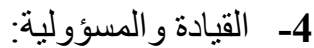

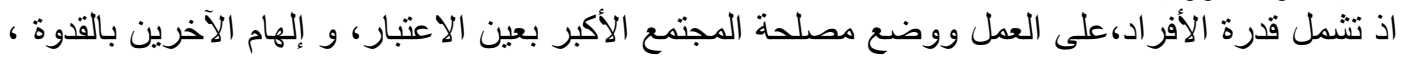

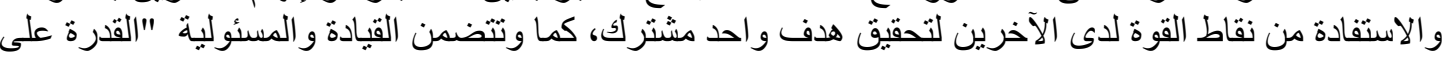

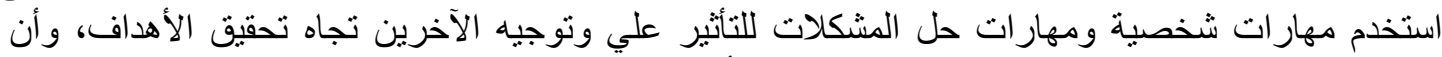

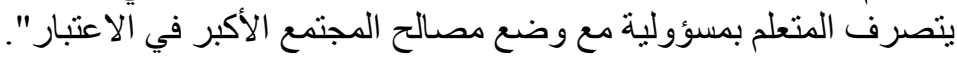

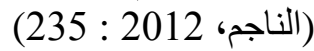

ادوار المعلم في مواجهة تحديات القرن21 :

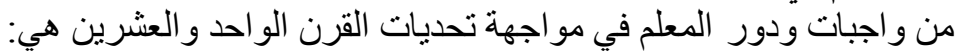

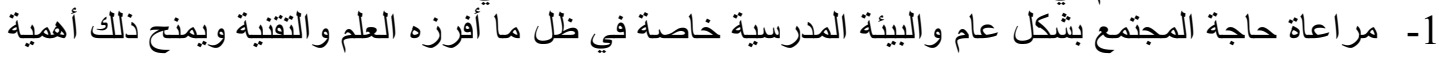
مناسبة عند التدريس. 2- الاهتمام بمعاونه الطلبة في تحصيل العلوم الحديثة وخلق معارف جديدة من خلال التو اصل و التعاون بفعالية

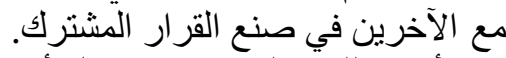

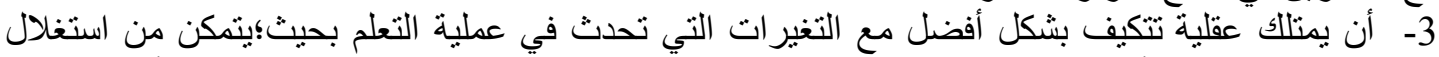

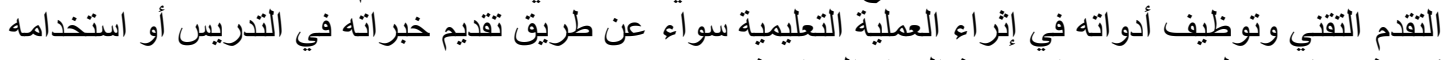

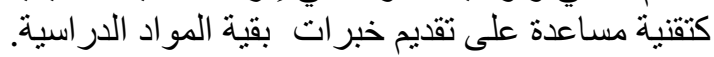

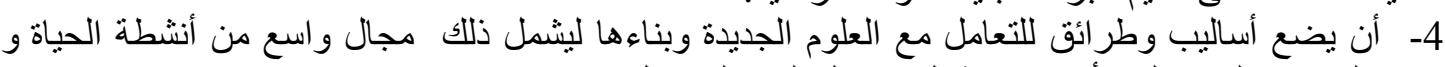

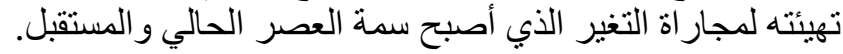

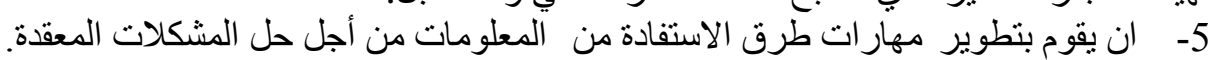
(Faulkner and Latham, 2016: 137) المحور الثاني: الدراسات السابقة

توصل الباحثٌ إلى بعض المواتشرات الماتئة والدلالات للار اسات السابقة الموضحة كالأتي الجدول ( 1 )

\begin{tabular}{|c|c|c|c|c|c|c|c|}
\hline نتائج الاراسة & الإحصائية & العينة & منهجة & أداة الدراسة & هدف الدراسة & الاراسة & الدراسة \\
\hline 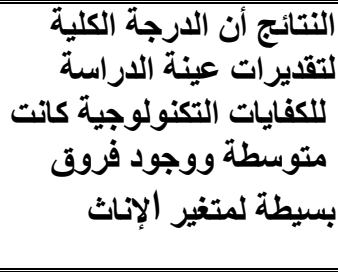 & والثنائيل التباين & مديراً & التوصفيجي & الاستخبنة، & 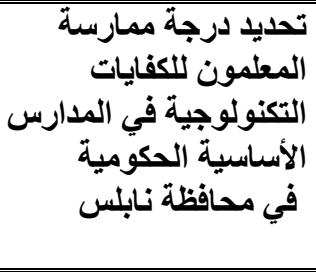 & فلّطين & 1- در اسةة زامل \\
\hline ضان أداء عهينة الدراسة في & تالحاديل التباين & $\begin{array}{l}\text { معلما (131) } \\
\text { معا }\end{array}$ & الوصنهي & بناؤها في ملاحظة تم & تقويم التدريس الرياضيات & السعودية & 2- دالقطة الغامدي (2016) \\
\hline
\end{tabular}


المجلة اللحولية اللملوم الآسانية والإمتصاعية International Journal of Humanities and Social Sciences website:www.ijohss.com Email:editor@ijohss.com ISSN: $2415-4822$

العدد (16) أكتوبر 2020 Volume (16) October 2020

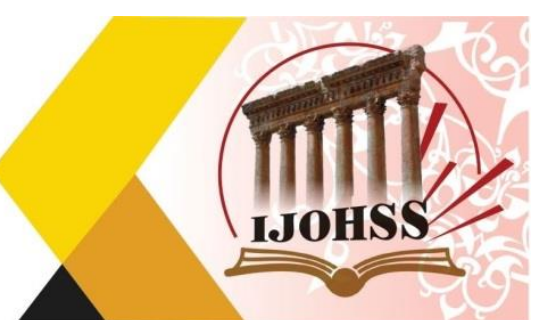

IJOHSS

\begin{tabular}{|c|c|c|c|c|c|c|c|}
\hline الحعادي والعشرين للقرن ان & واختبار شيفيه & الرياض بمدينة & التحليلي & والقرن الحادي & 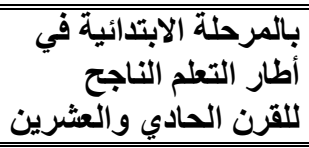 & & \\
\hline 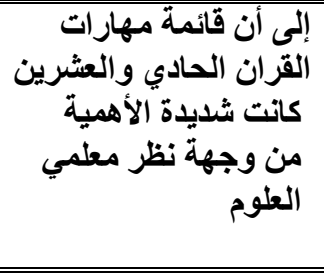 & الثبتات الاستبانة & علومة & الوصنهي & والقائمة بمهارات & 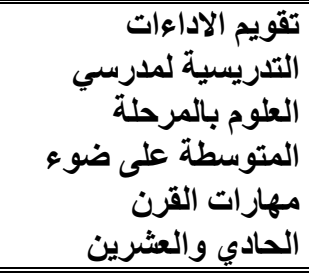 & السعودية & 3-دراسة الحطيبي \\
\hline 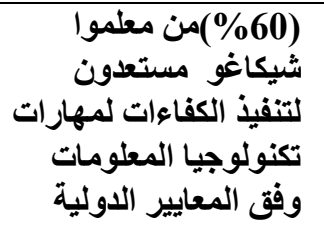 & $\begin{array}{r}\text { الأحليل التبادين } \\
\text { t- test } \\
\text { التيفيل }\end{array}$ & مُ معلما & الوصنهج & الأستبانة & 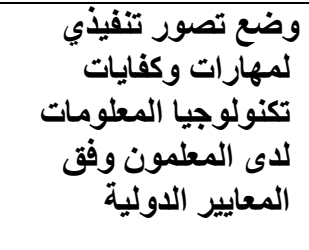 & أمريكا & 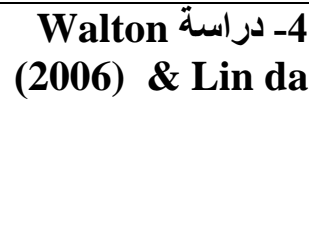 \\
\hline 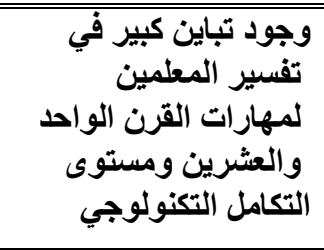 & $\begin{array}{r}\text { الأحادين } \\
\text { Ánova }\end{array}$ & ثمان & التوصنهيج & والجاقةّالملاحظة & 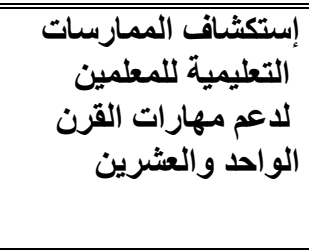 & أمريكا & 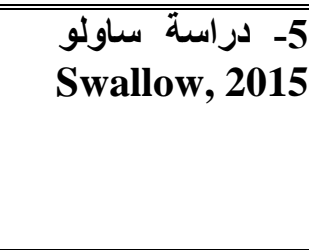 \\
\hline
\end{tabular}

المؤشرات والالالات للار اسات السابقة:

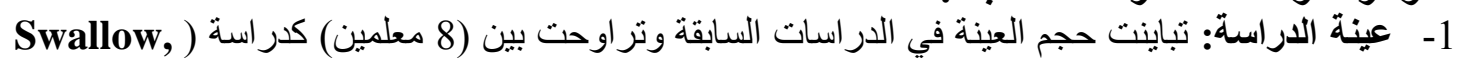

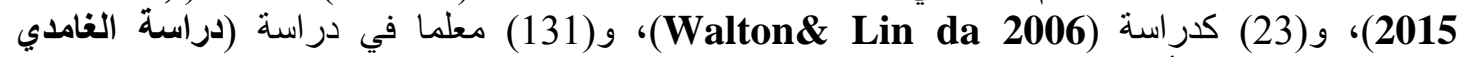

و القحطاني (2016). أما الدر اسة الحالية استخدمت حجم العينة(232) مدرس ومدرسة.

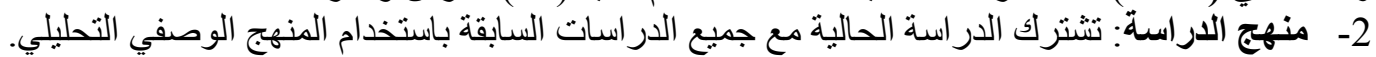

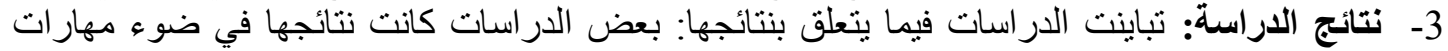

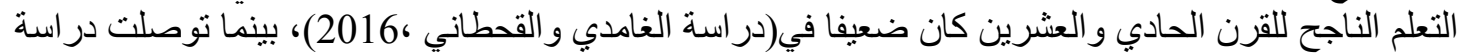

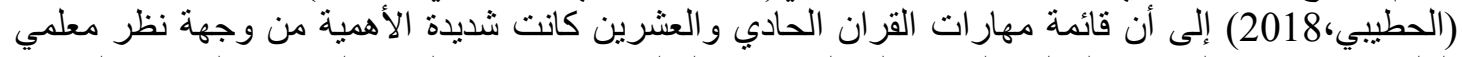

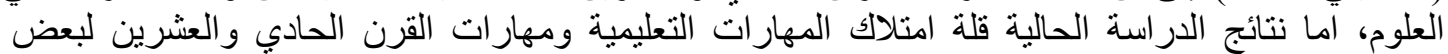

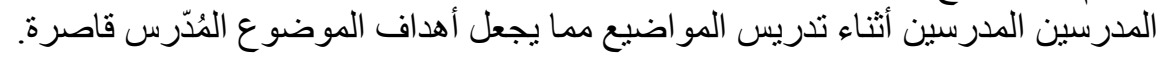

الفصل الثالث/ منهجية البحث البه البه

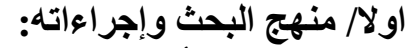

بمكن للباحث أبث يحدد منهج البحث على وفئ وفق الأبعاد التي يهتم بها أثناء عمله البحثي، وقد يحدد أكثر من منهج

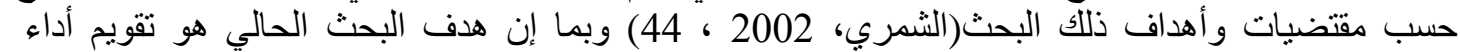

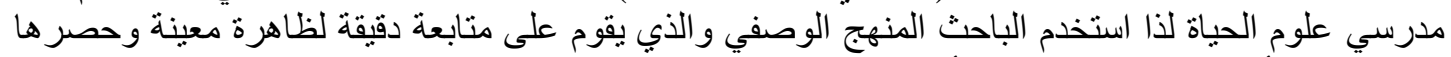

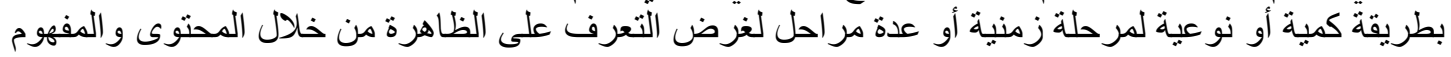

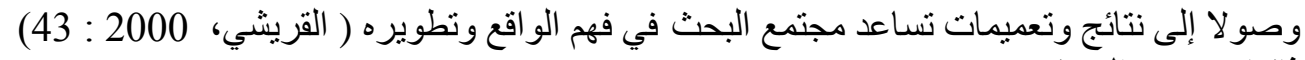

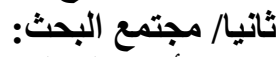

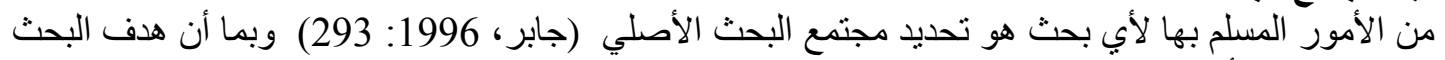

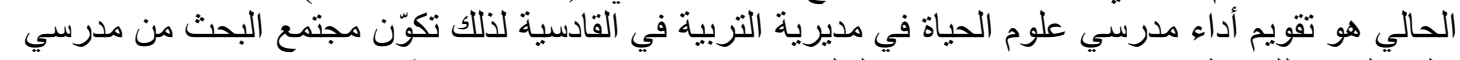

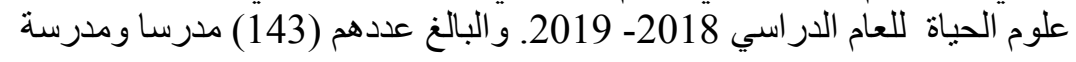


العدد (16) أكتوبر 2020 (16)

ISSN: $2415-4822$

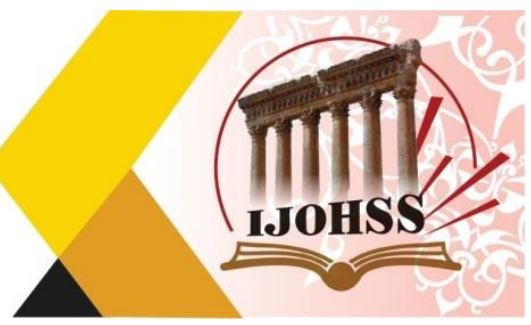

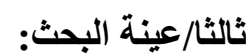

يقصد بالعينة إنها "جزء ء من مجتمع البحث يتم اختيار ها على وفق قو اعد وأسس علمية لتمثيل المجتمع تمثيلاً

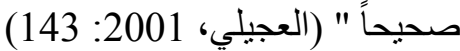

اختار الباحث عشو ائيا (32) مدرس من مختلف المدارس ليمنلون عينة البحث وبنسبة 22\% بو اقع (16)

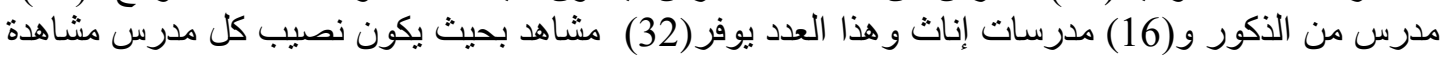
واحدة في تدريسه المادة . رابعا/ توزيع عينة البحث: نم توزيع عينة البحث على البحث أساس متغير الخدمة إذ قسمت عينة البحث على ثلاث مستويات و على النحو الآتي:

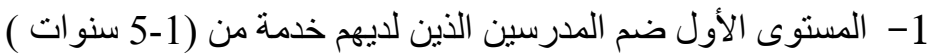

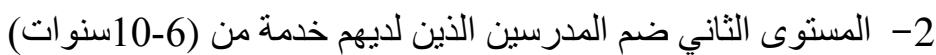

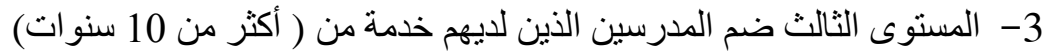

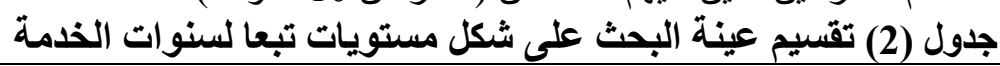

\begin{tabular}{|c|c|c|c|c|}
\hline \multirow[t]{2}{*}{ سنو ات الخدمة } & \multirow[t]{2}{*}{ ال المجموع } & \multicolumn{2}{|c|}{ جنس المدرسين } & \multirow[t]{2}{*}{ المستوى } \\
\hline & & إ إناث & ذ ذ ذكور & \\
\hline من 1-5 سنوات & 10 & 5 & 5 & المستوى الاول \\
\hline من 6-10 سنوات & 12 & 5 & 7 & المستوى الثاني \\
\hline اكثر من 10 سنو ات & 10 & 6 & 4 & المستوى الثالث \\
\hline \multicolumn{2}{|c|}{32} & 16 & 16 & المجموع \\
\hline
\end{tabular}

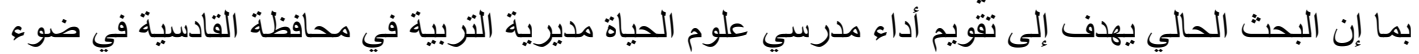

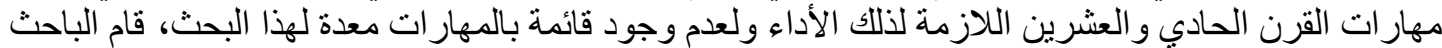

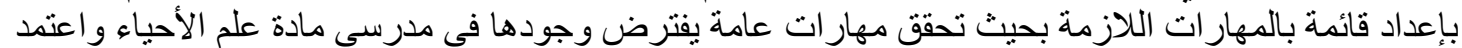

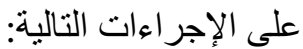
1- - ملاحظة عدد من المدرسين في أثناء التندريس في مدارسهم الثانوية و المتوسطة.

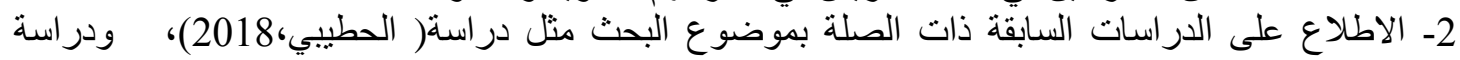

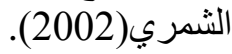

3 - الاطّلاع على الأدبيات التي تعنى بتدريس مو اد علوم الحياة.

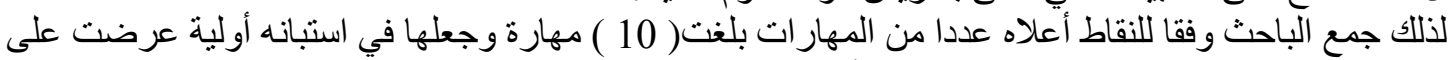

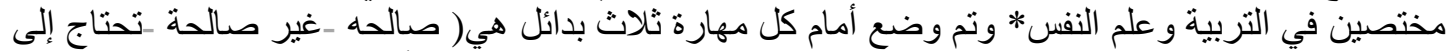

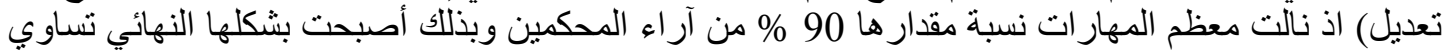

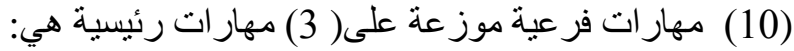

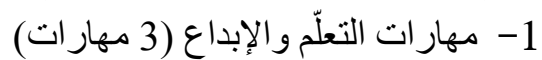

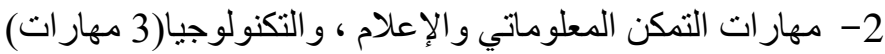

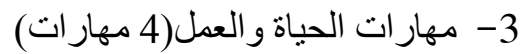
ولغرض تحديد ذاتية تقدير الملاحظ لألأداء مدرسي مادة علم الأد الأحباء في تدريس المواد وجعل الملاحظة

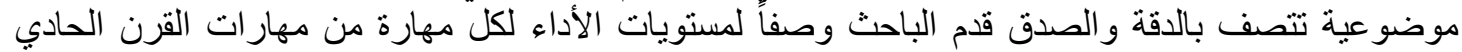

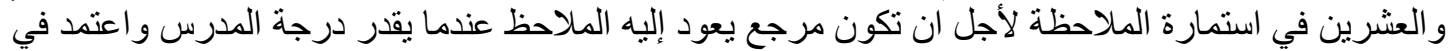
وصف الأداء على ما يأتي:

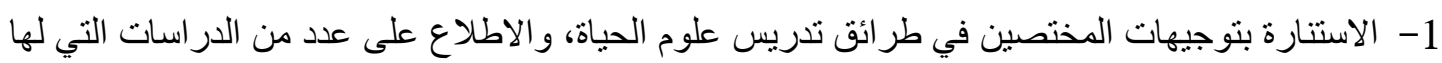

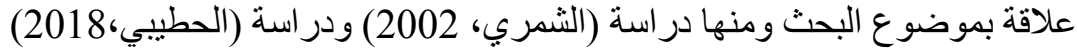


العدد (16) أكتوبر 2020

Volume (16) October 2020

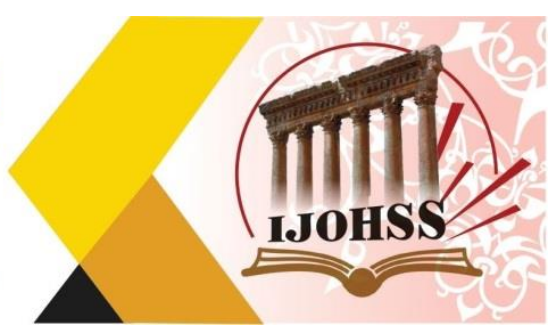

2- زيارة عدد من المدرسين في صفوفهم أثناء تدريسهم للمو اد للاطلاع على أدائهم في أثناء تأديتهم لكل درس الأد إداء

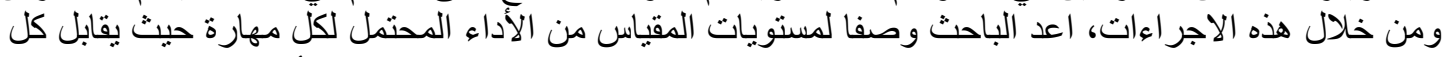

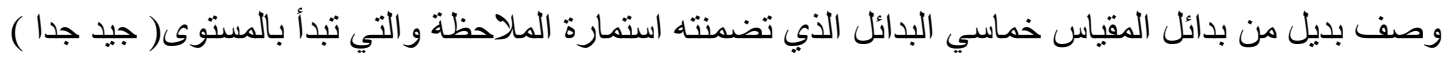

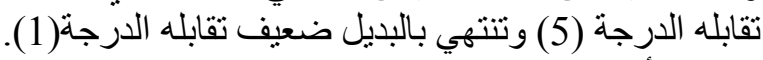

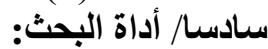

اعتمد الباحث الملاحظة كأداة بحثيه في بحثه و التي تعرف بأنها "المشاهدة الدقيقة التي تحدد السلوك وتسجل

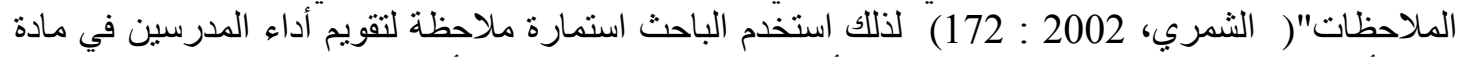

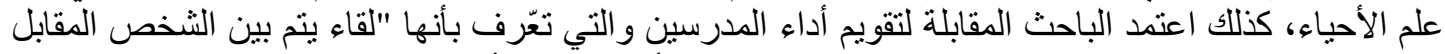

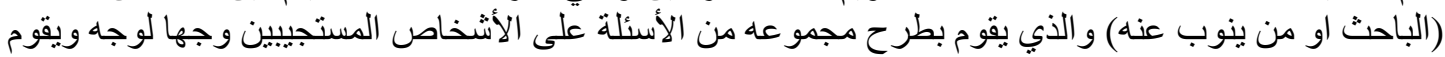

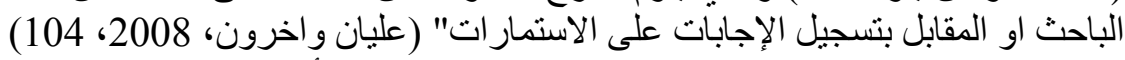

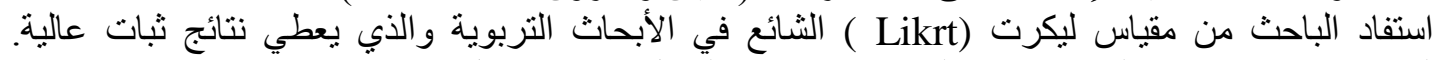

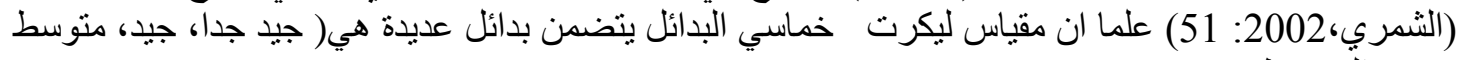

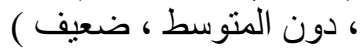

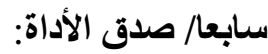

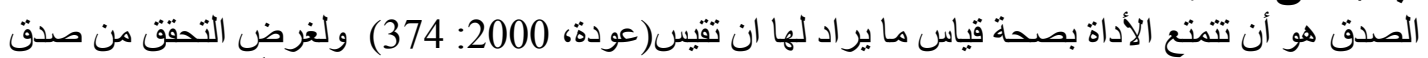

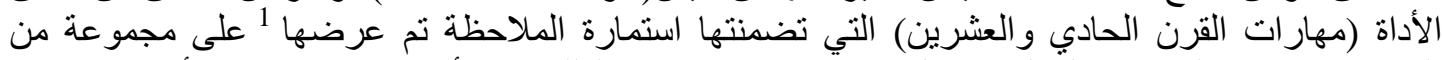

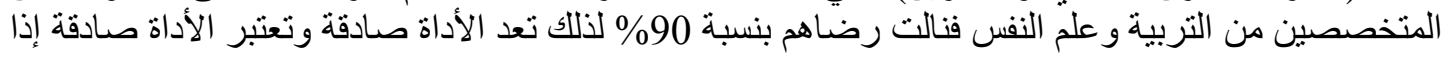
كانت معامل صدقها تتجاوز 80\%

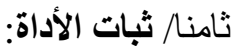

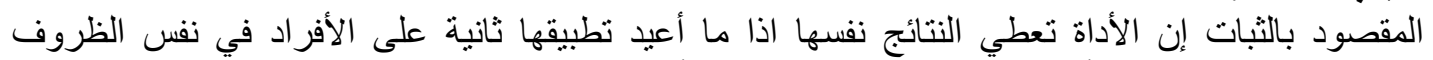

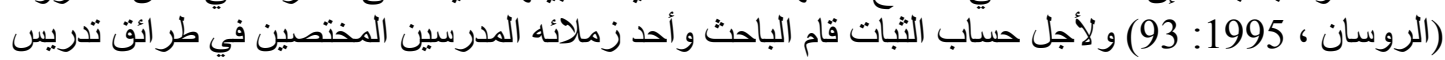

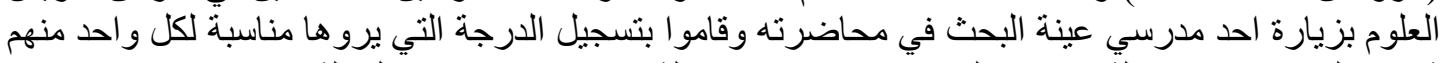

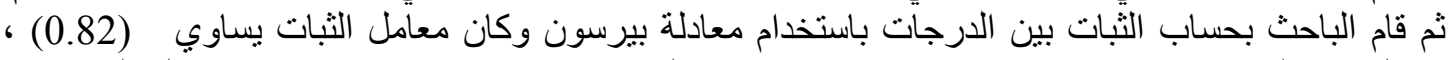

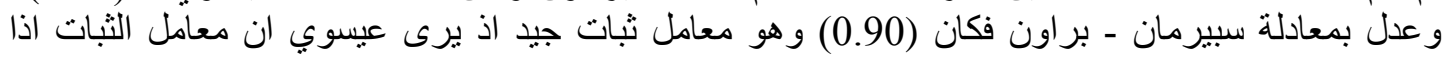

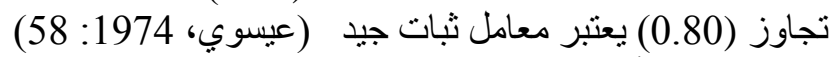

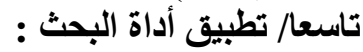

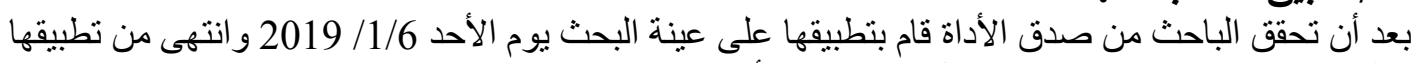

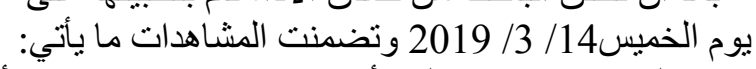
1ـ مقابلة مدرسي مادة علم الأحياء في قاعاتهم وتعريفهم بأهداف البحث وانئ وانه لأغر اض البحث العلمي لكي يكون أدائهم اعنيادي. 2- الاطلاع على دفاتر الخطة اليومية و الملاحظات لأفر اد عينة البحث لتدوين البيانات الخاصة في المهار اتلات.

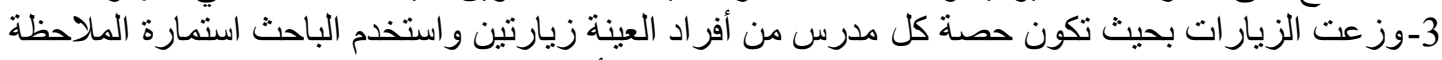

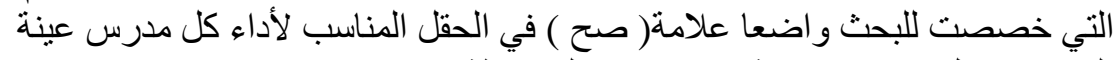
البحث في كل مهارة مضمنة في استمارة الملاحظة. عاثر / الَّسائل الإحصائية: استخدم الباحث الأدوات الإحصائية الإنية الآتية: 1- الوسط الحسابي لإيجاد متوسط الأداء العام.

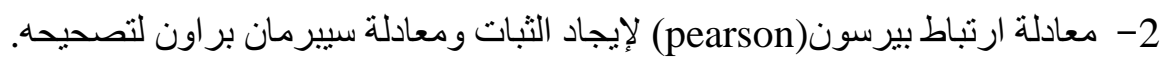

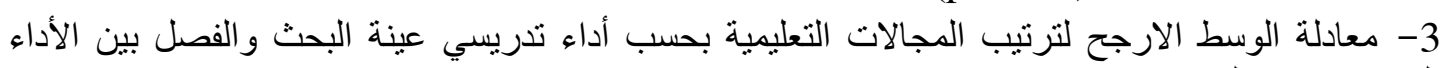
المتحقق وغير المتحقق الإد

$$
1 \text { فر أ.م.د احسان حميد جبر ، أ.م.- مازن ثامر شنيف- م.د مسلم محمد النبهان- م.د احمد حمزة- م.م. وسام جاسم خلف- م.م }
$$


العدد (16) أكتوبر 2020

Volume (16) October 2020

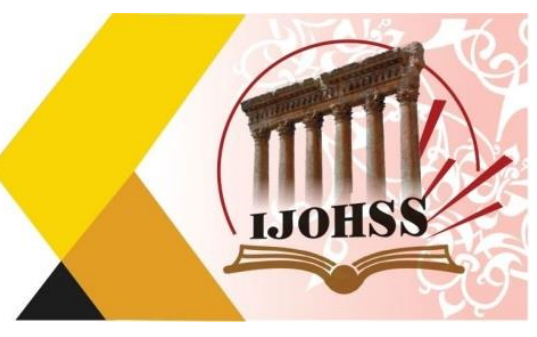

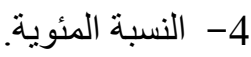

الفصل الرابع: عرض النتائج وتفسيرها

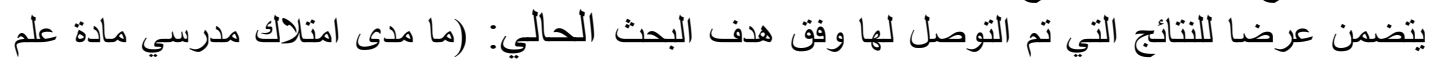

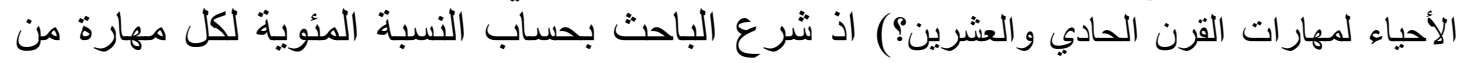

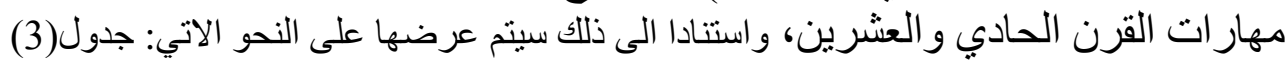
جدول(3) النسب المئوية لمهارات القرن الحادي والعشرين

\begin{tabular}{|c|c|c|c|c|c|c|c|c|}
\hline \multirow[t]{3}{*}{ الارجح } & \multirow[t]{3}{*}{ المئوية } & ضعيف & الوسط & متوسط & جيذ & جيد جدا & \multirow[t]{3}{*}{ المهارة } & \multirow[t]{3}{*}{ ت } \\
\hline & & العدد & العلد & العدد & العدد & العدد & & \\
\hline & & $\%$ & $\%$ & $\%$ & $\%$ & $\%$ & & \\
\hline 4.21 & $\% 84$ & $\mathbf{0}$ & 1 & 3 & 16 & 12 & التفكير الناقد وحل المشكلات & 1 \\
\hline 4.03 & $\% 81$ & 2 & 1 & 4 & 12 & 13 & الاتصال والتشارك & 2 \\
\hline 2.906 & $\% 58$ & 7 & 7 & 6 & 6 & 6 & الابتكار والإبداع & 3 \\
\hline 1.87 & \%38 & 13 & 13 & 4 & $\overline{1.1}$ & $\overline{1}$ & الثقافة المعلوماتية & $\overline{4}$ \\
\hline 2.125 & $\% 43$ & 12 & 10 & 6 & 2 & 2 & ثُقافة الوسائط الإعلامية & $\overline{5}$ \\
\hline 2.93 & $\% 59$ & 8 & 6 & 5 & 6 & 7 & ثقافة تقنيات المعلومات والاتصال & $\overline{66}$ \\
\hline 4.62 & $\% 99$ & 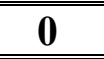 & $\overline{\mathbf{0}}$ & 1 & 10 & 21 & المرونة والتكيف & 7 \\
\hline 3.75 & $\% 75$ & 2 & 3 & 6 & 11 & 10 & المبادرة وتوجيه الأات & 8 \\
\hline 3.87 & $\% 77$ & 2 & $\overline{4}$ & 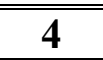 & $\overline{12}$ & 11 & الإنتاجية والمسـاعلة & $\overline{99}$ \\
\hline 3.81 & $\% 76$ & 1 & 2 & 8 & 12 & 9 & القيادة والمسؤولية & 10 \\
\hline
\end{tabular}

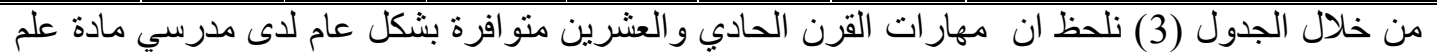

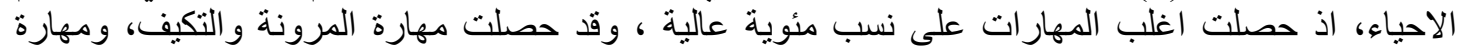

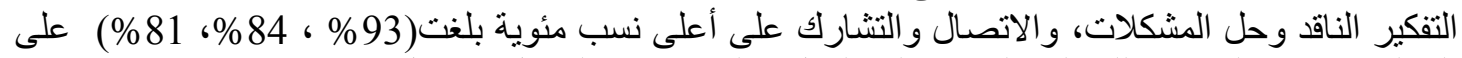

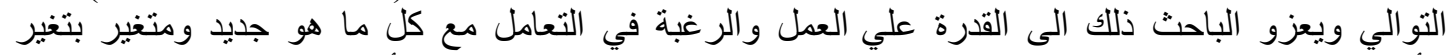

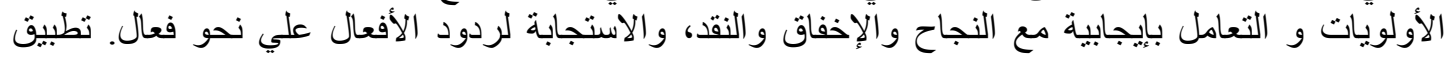

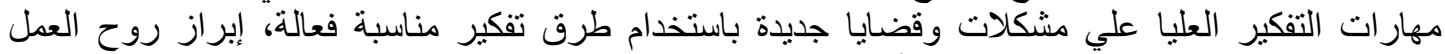

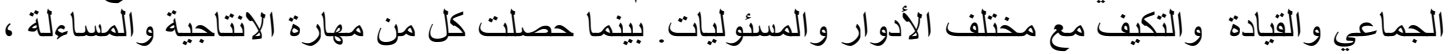

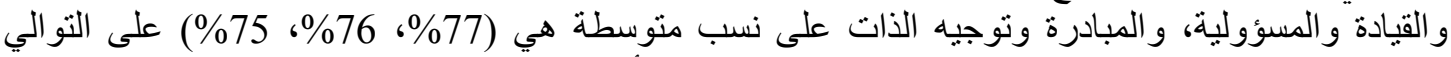

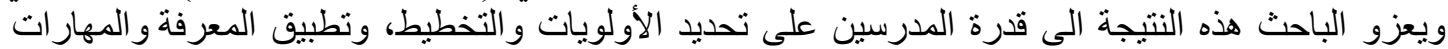

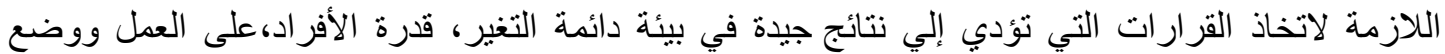

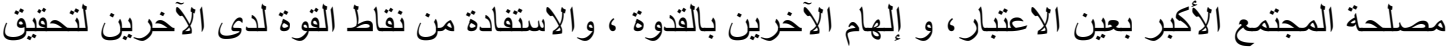

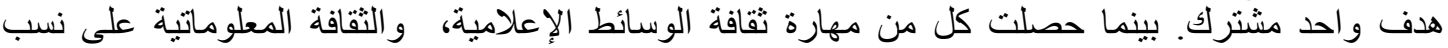

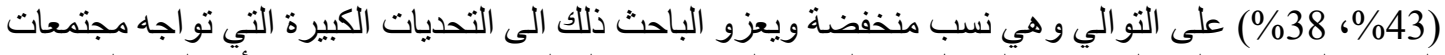

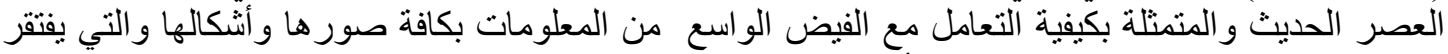

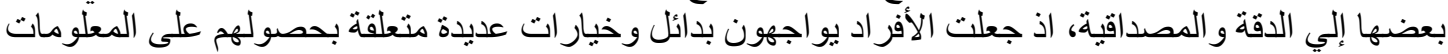
سو اء في الدراسة أو العمل او في حياتهم الثخصية. 


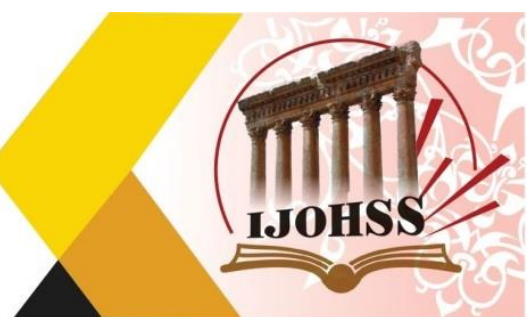

أولا/ الاستنتاجات: نتائج البحث الحالي أفضت ما يأتي:

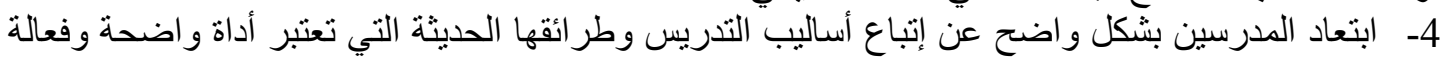

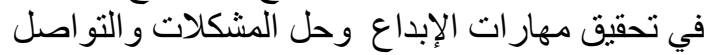
5- نسلط بعض المدرسين و عدم اتصافه بالثفافية و المرونة مع طلبتهم و هذا يعود إلى ضعف الخبرة ونقص الإعداد المهني لبعضهم. 6- قلة امتلآك المهارات التعليمية ومهار اتلهات القرن الحادي والعشرين لبعض المدرسين أثناء تدريس المواضيع

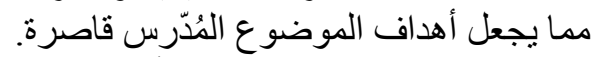
7- عدم وجود معايير تقويمية لأغلب المدرسين للمهار ات المضنمنة في المواضيع التي يدرسونها. ثانيا/ التوصيات: استنادا إلى النتائج التي نوصل إليها البحث يوصي الباحث بما يأتي:

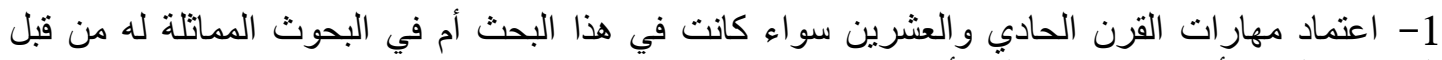
المدرسين لتقويم أدائهم في مادة علم القم الأحياء.

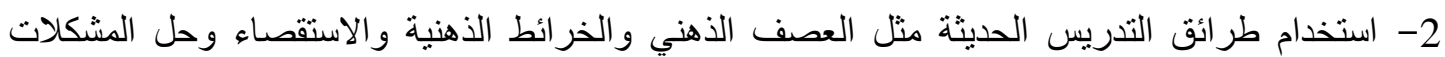
و غير ها أثناء التدريس و التي تؤدي إلى زيادة التقة بالنفس و الجر أة و النقاش وتحمل المسؤولية فئها.

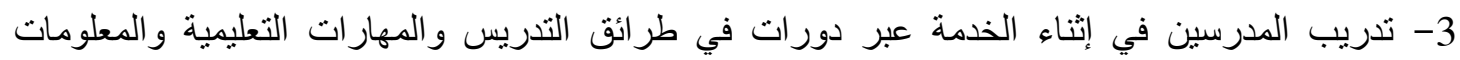

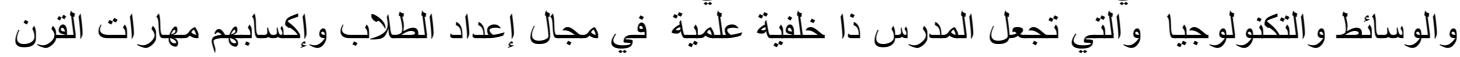

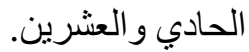
4- العمل على تمكين المدرسين من تقويم دروسهم وعرضها ومناقتشتها بعد تخطيطها وتهيئنها وتضمينها

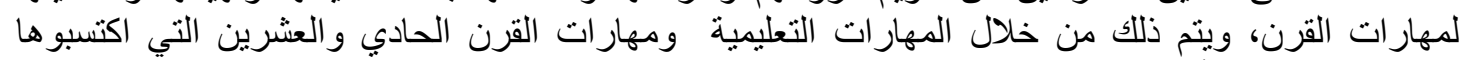

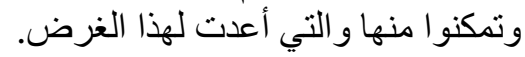
5- إدر اج مهار ات القرن الواحي اعد والعشرين ضدمن المواد الدراسية في كليات التربية و العلوم ولكافة المر احل الدر اسية في هذه الكليات.

ثالثار المقترحات: اعتماداً على نتائج البحث يقترح الباحث ما يأتي:

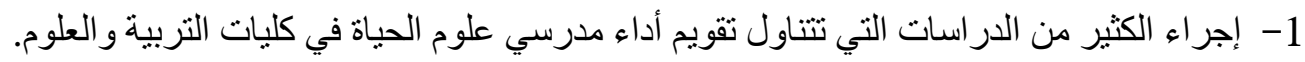

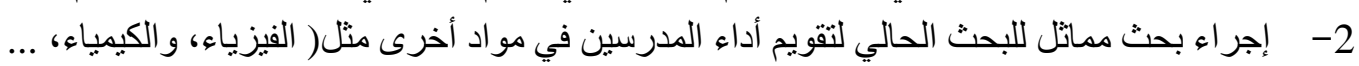
3- إجر اء بحث مماثل للبحث الحالي في المرحلة الجامعية لغرض إعداد المدرسين في تلك المر المر احل التي تعتبر أساس تهيئة المدرس لهذه المهنة المقدسة. 4- إجراء بحث يتناول الصعوبات التي تعترض المدرسة لهدرسين في إثناء عملية التدريس وفي استخدام طر ائق

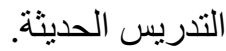
5-التأكيد على اقامة الندوات أو الدورات التي تتناول أساليب القيادة وتحمل المسؤولية و الاتصال و الوصول إلى

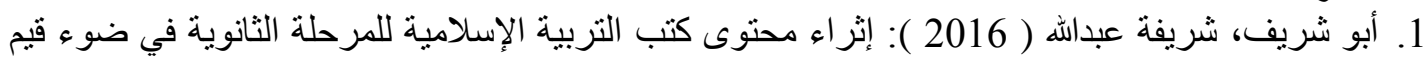

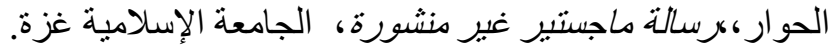

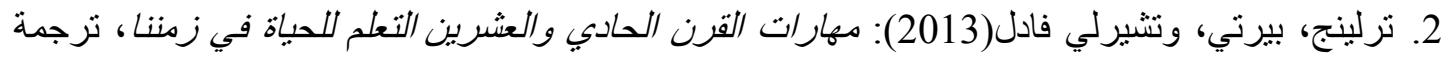

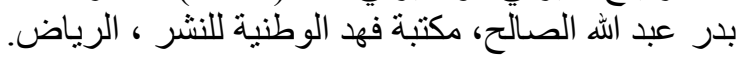

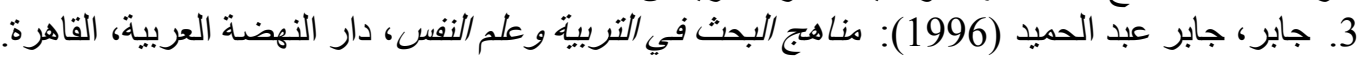

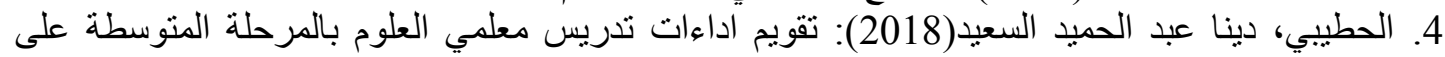

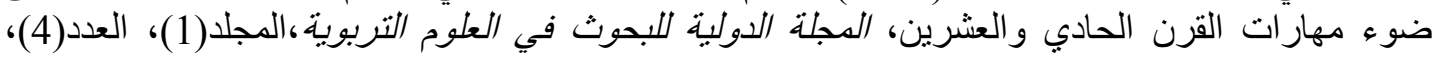

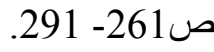


العدد (16) أكتوبر 2020

Volume (16) October 2020

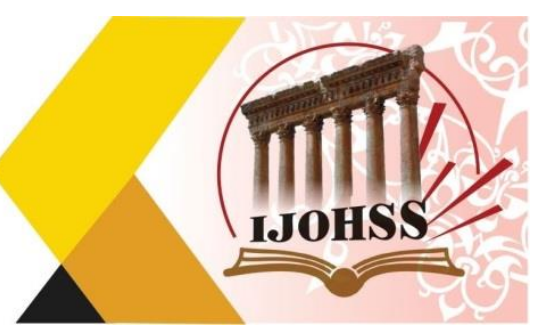

5. حفني، مها ( 2015) : مهار ات معلم القرن الحادي و العشرين ، المؤتمر العلمي الرابع و العشرين للجمعية المصرية للمناهج ، مجلد(24)، جامعة أسيوط، مصر .

6. حلس، داود درويش وأبو شقير، محمد ( 2017 ) ): محاضرات في مهارات التدربي، متاح عبر : http://www.softwarelabs.com

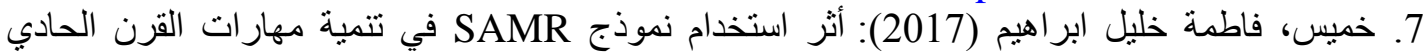

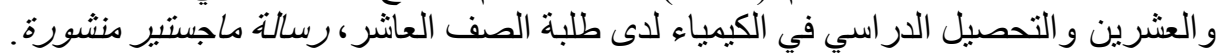

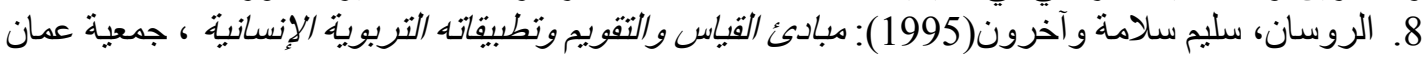

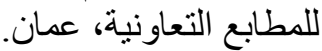

9. الزهر اني، أحمد، و ابر اهيم، يحيى ( 2012) : معلم القرن الحادي و العشرين، مجلة الدعرفة، العدد (11) ، مثتوفر على: http://almarefh.net/show_content_sub.php

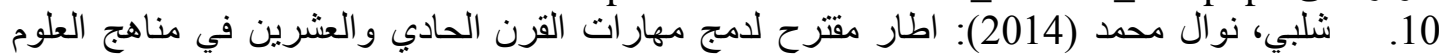

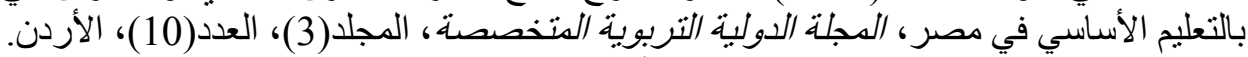
11.

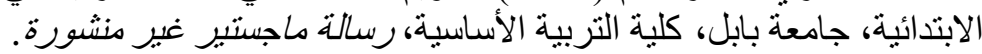

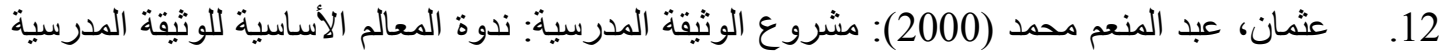

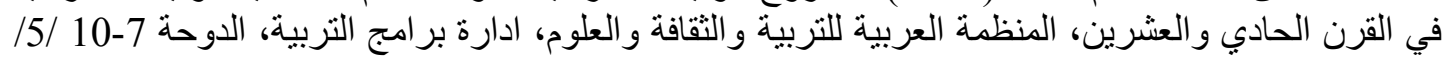
. 2000

13. العجيلي، صباح حسين و آخرون(2001): مبادئ القياس و التقويم التربوي، دار الكتب و الوثائق، مكتب الدباغ للطباعة، بغداد. 14. عمان، دار صفاء.

15. عودة، احمد (2000): القياس والتقويم في العملية التدريسية ـ دار الأمل للنشر و التوزيع، عمان. 16.

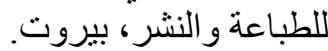

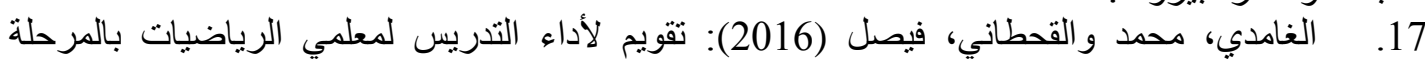

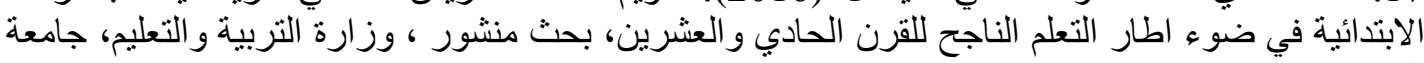
الملك خالد

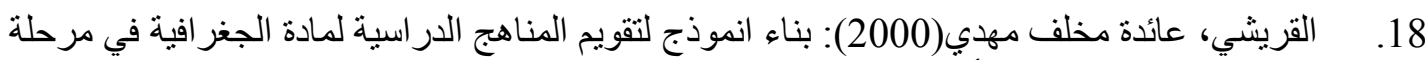

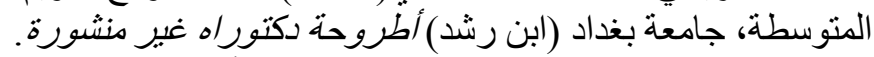
19.

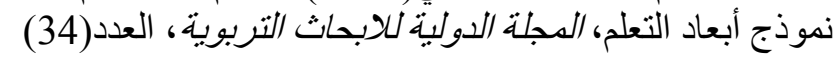

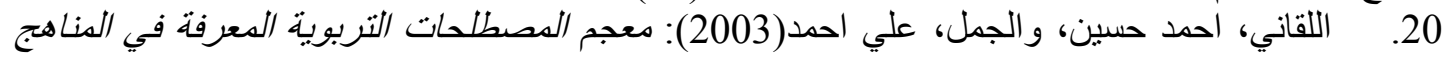

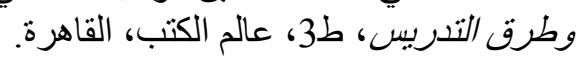

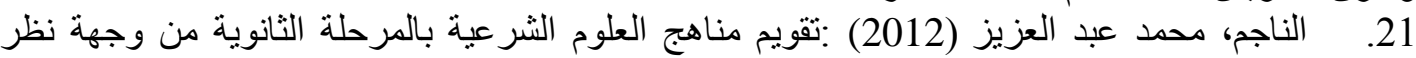
المعلمين في ضوء مها رات القرن الحادي و العشرين. المجلة الدولية للابحاث التربية بلتربية المجلد (3)، العدد (13)

22. Beers Z. Sue (2006): 21st Century Skills: Preparing students for their future. https://www.mheonline.com/.../21st_century_skills.pdf 23. Bybee, W. (2010): The Teaching of Science: 21st Century Perspectives NSTA press. Retrieved February 9, 2016, from: www.sbcf.fr

24. Facer, K. (2012): Taking the 21st century seriously young people, education and sociotechnical futures. Oxford Review of Education Vol. 38, pp 97-113. 
العدد (16) أكتوبر 2020

Volume (16) October 2020

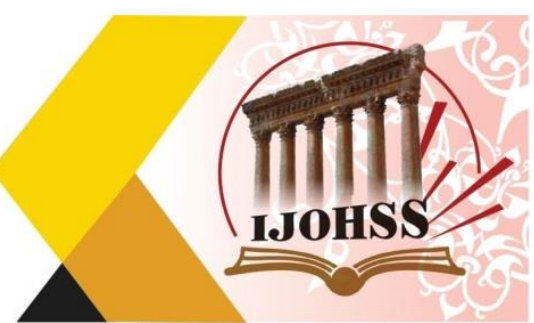

25. Faulkner, J., and Latham, G. (2016): Adventurous Lives: Teacher Qualities for 21st Century Learning Australian Journal of Teacher Education, 41 (4).

26. Guinn Patrick (2012): Mobilizing Mom and Dad: Engaging Parents behind Systemic School Reform, Madison, NJ $07940 \quad$ (973) 408-3425. Leadbeater C,( 2008): What's Next? 21 Ideas for $21^{\text {st }}$ Century Learning. London, The Innovation Unit. (Accessed 13 March 2014).

27. Starr, C. Manaris, B. and Stalvey, R. (2008). Bloom's Taxonomy Revisited: Specifying Assessable Learning Objectives in Computer Science. College of Charleston.

28. Swallow, M. (2015). Exloring catholic education in the 21st century.Teaching practices, technology integration, and educational goals. Univesity of Vermont Graduate College Dissertations and Theses.

29. Walton,T.; \& Linda, B.,(2006). Information Technolog y Teachers' Perception Of Implementing The National Education Technology Standards, Colorado State University

30. Web (2007). " The e-learning competency framework for teachers and trainers," available at: www.oph.fi/attachment?/path

31. The National Science Teachers Association ,2013: Quality Science Education and 21st-Century Skills.

www.innovationunit.org/sites/ 